\title{
Modelling the Food Availability and Environmental Impacts of a Shift Towards Consumption of Healthy Dietary Patterns in Australia
}

\author{
Seona Candy ${ }^{1, *(\mathbb{D})}$, Graham Turner ${ }^{2}$, Kirsten Larsen ${ }^{2}$, Kate Wingrove ${ }^{3}\left(\mathbb{D}\right.$, Julia Steenkamp ${ }^{4}{ }^{(\mathbb{D}}$, \\ Sharon Friel ${ }^{5}$ and Mark Lawrence ${ }^{3}$ (i) \\ 1 Helsinki Institute of Urban and Regional Studies (Urbaria), University of Helsinki, 00014 Helsinki, Finland \\ 2 Melbourne Sustainable Society Institute, University of Melbourne, Melbourne 3010, Australia; \\ contact@earthaccounts.com.au (G.T.); kirsten@openfoodnetwork.org.au (K.L.) \\ 3 Institute for Physical Activity and Nutrition (IPAN), Deakin University, Geelong 3220, Australia; \\ k.wingrove@deakin.edu.au (K.W.); mark.lawrence@deakin.edu.au (M.L.) \\ 4 Faculty of Agriculture and Veterinary Sciences, University of Melbourne, Melbourne 3010, Australia; \\ julia.steenkamp@unimelb.edu.au \\ 5 School of Regulation and Global Governance (RegNet), Australian National University, \\ Canberra 0200, Australia; Sharon.Friel@anu.edu.au \\ * Correspondence: seona.candy@helsinki.fi; Tel.: +35-8504-750-915
}

Received: 15 November 2019; Accepted: 9 December 2019; Published: 12 December 2019

\begin{abstract}
Dietary change has been suggested as a key strategy to maintain food security, improve health and reduce environmental impacts in the face of rising populations, resource scarcity and climate change impacts, particularly in developed countries. This paper presents findings from a quantitative modelling analysis of food availability and environmental implications of shifting the current average Australian dietary pattern to one of two alternative, healthy dietary patterns, the 'healthy mixed diet', with a mixture of animal and plant foods, and the 'healthy plant-based diet', with only plant foods. Both were constructed in accordance with the Australian Dietary Guideline recommendations, and four sustainability principles: Avoiding over-consumption, reducing intake of discretionary foods, reducing animal products, and reducing food waste. It was assumed that all food was provided domestically where possible, and export of foods only occurred when there was a surplus to domestic requirements. The authors compared the impacts of each dietary pattern on direct food availability, water use, land use, greenhouse gas emissions, fuel and energy use and fertiliser use. The plant-based diet had the best overall environmental and direct food availability outcomes, however had key vulnerabilities in terms of fertiliser and cropping land availability. For the agricultural sector overall, changes in diet had little effect on environmental impact due to the amount and nature of Australian exports, indicating that changes to production methods are also necessary. Likewise, changing diets had little effect on the existing environmentally intensive Australian economy, indicating that changes to other sectors are also necessary.
\end{abstract}

Keywords: healthy and sustainable diets; nutrition; environment; food security; agriculture

\section{Introduction}

Concerns regarding threats to future food security are well documented [1,2]. Globally the population is expected to reach nine billion by 2050 , and already, the food system is failing to meet the nutrition needs of hundreds of millions of people [2,3]. Furthermore, there is a growing concern that dietary consumption patterns in high-income countries, and emerging trends in dietary patterns in 
developing countries are not only unhealthy but also environmentally unsustainable, to the extent that they will exceed planetary boundaries and hinder food production in the future $[4,5]$.

Developing healthy, fair and environmentally sustainable food systems will be essential if the United Nation's Sustainable Development Goals (SDGs) are to be achieved. This realisation has prompted researchers around the world, including Australia, to look more closely at foods and dietary patterns that are both healthy and sustainable and that contribute to the mitigation of climate change. Most frequently, studies have reported that reducing animal products in the diet and replacing them with plant-based foods has the greatest impact [6-11]. Studies have also reported that decreasing energy intake in line with recommended levels, as well as decreasing the consumption of discretionary or 'ultra-processed' foods, is important for both health and environmental sustainability [12-14]. Finally, in order to ensure that resources are being used in the most efficient way possible to meet health needs, it is also important to reduce food waste [15].

Although the majority of studies have reported that healthy diets are also sustainable diets [14, 16-18], some studies have identified discrepancies [19,20]. Vieux et al. [20] argue that without calorie reduction, substituting animal products with plant-based foods is of no benefit to the environment due to the large amount of fruits and vegetables needed to make up for the calorie shortfall. The sustainability and nutritional value of the diet will depend on specific food choices within food groups and must also consider how the food was produced (i.e., farming method), geographic region, transport method and growing conditions.

Most recently, the release of the EAT Lancet Commission report represents the culmination of many of these research threads [21]. This major study integrated scientific targets for healthy diets and sustainable food systems into a common framework to define a safe operating space for food systems. The aim was to enable the assessment of which diets and food production practices will help ensure that the UN Sustainable Development Goals (SDGs) and Paris Agreement are achieved. A universal healthy reference 'planetary diet' was developed to provide a basis for estimating the health and environmental effects of adopting an alternative diet compared to standard current diets. The reference diet is particularly low in meat products, as a result, the transformation to such a diet would require substantial dietary shifts. The reference diet has generated significant criticisms based on the low meat recommendations from both a health and environmental perspectives, particularly around its feasibility for different countries and regions [22]. This indicates that further regional or national focused research into food availability, healthy and sustainable diets, and food systems sustainability is needed to complement, contextualise or potentially challenge these global scale recommendations.

Australia is widely considered to have a high level of food security. Food production exceeds the local demand [23] and 60\% of agricultural production (by volume) is exported [24]. As a high-income country, it is generally assumed that Australia will always be able to import whatever foods are needed [25] to protect food security. There are, however, significant potential threats to Australia's long-term food security, including both import and export capabilities. These include climate change [26,27], land degradation [28], water scarcity [29], oil and fertiliser dependence [30], competition for agricultural land from other sectors [27,31], foreign land ownership [27,31] and economic factors such as accelerating international debt [29]. In light of recent political events in the USA and UK and a move towards more protectionist policies, the ability of Australia to maintain direct food availability is becoming increasingly topical [32]. Direct food availability is a measure of the resilience of the Australian food system and refers to the ability to produce the food required to meet the nutritional needs of the population from within Australia's borders, but does not imply 'food security' as it does not consider factors such as access, stability and utilisation.

Previously the authors have reported the findings from their analysis of 'The Path We're On' (TPWO) scenario, a representation of the current 'average' Australian diet that was developed drawing on food consumption data derived from the Australian 2011/12 National Nutrition and Physical Activity Survey (NNPAS) [33]. It was found that the current food consumption trends in Australia are environmentally unsustainable, unhealthy and costly. Results also showed that Australia is already 
heavily reliant on imports of seafood, and by 2040 may also be reliant on imports of some major agricultural commodities such as nuts and dairy due to increased domestic demand and factors impacting food production such as climate change, land degradation and finite limits on resources. This has implications for other countries with limited domestic production capacity or high domestic demand that depend on Australian food exports, such as Japan, China and Indonesia [34,35]. More importantly, it has implications for feeding a growing domestic population in an increasingly food insecure world, subject to global food system shocks that may disrupt food supply chains and inflate food prices.

Other studies have investigated limited aspects of alternative diet scenarios in the Australian and other regional or national contexts. Hendrie et al. [14] modelled different diets in Australia and found that a healthy diet had 25\% lower greenhouse gas emissions (GHGEs). Ridoutt et al. [32] examined a conventional and healthy diet scenario from a nutritional balance and import reliance perspective based on linear projections for national agricultural production. Blackstone et al. [36] investigated the environmental impacts of different recommended healthy dietary patterns in the US context. As of yet, however, no study has investigated both multiple environmental impacts and direct food availability implications of alternative diets based on more complex, non-linear agricultural production projections at a national or regional level, which is necessary to give a more comprehensive picture of food, sustainability and health issues.

This paper builds on previous work by investigating the direct food availability and environmental implications of implementing strategies that shift Australia's current dietary pattern to one or other of two healthier dietary patterns, a 'mixed' diet consisting of a mixture of animal and plant foods, and a 'plant-based' diet containing only plant foods. The Australian Stocks and Flows Framework (ASFF) [37] was used to model the different scenarios allowing trade-offs between different sustainability indicators and structural change to be explored, argued as necessary in improving food system assessment by Hadjikakou et al. [38]. First, the overall consumption volume and composition were calculated for each diet (Section 3). Then, the possibility of achieving 'direct food availability' was examined (Section 4). Multiple environmental impacts of changes to domestic food consumption and total agricultural production (for both domestic consumption and for export) were then calculated and compared for each diet scenario (Section 5). Finally, these findings were discussed in terms of local and global food security, sustainability and resilience. It is intended that the findings from this research will help inform decision-making for future nutrition policies and interventions to help promote healthy and sustainable diets in Australia.

\section{Interdisciplinary Scenario Modelling Methodology}

Scenario modelling can be a powerful tool to explore potential futures, consider how combinations of key trends and uncertainties could lead to different outcomes, and inform strategic choices and action [39]. In scenario modelling, qualitative scenarios are first created from which trends, policy positions and assumptions are then translated into quantitative scenario settings for a model to enable computational analysis of relationships and outcomes. These settings include both trends whose future impacts are relatively certain, and uncertainties or forces of change whose impact is unpredictable. The trends are incorporated across all scenarios, while the uncertainties provide the points of difference between them. Proposing several alternative scenarios underlines that there is not one pathway into the future. Most scenarios are described in their extremes, thus underlining the different variables and their relation to each other. In reality, the most feasible future pathway will be some combination of these.

Assessments of food systems are increasingly using scenario modelling to explore multiple possible futures for food security [32,40]. In some cases, however, this method has been criticised as too simplistic and techno-optimistic when applied to complex global food system issues [41]. At a national level, however, they can provide a quantitative evidence base for further research as part of a socio-technological-ecological approach to addressing food security and food system issues. 
In this study, the authors have drawn on the qualitative TPWO scenario and associated cross-sectoral quantitative settings [33] and used the Australian Stock and Flows Framework (ASFF) to model different diet scenarios. ASFF is a dynamic scenario modelling platform designed to comprehensively assess Australian environmental sustainability challenges and identify tensions that arise from competing demands on resources within Australia [37]. Common trends across scenarios include population growth, climate change impacts and agricultural efficiency improvements. The points of difference include diet composition, particularly the reduction of animal products, discretionary foods and over-consumption above energy requirements based on recommendations from Friel et al. [12], as well as a reduction of food waste.

In the scenarios, it is assumed that there are no changes to long-term trends in how agricultural production occurs. This simplifying assumption enables the examination of only the effects of dietary change in the context of population and environmental change. Therefore, these scenarios and results are considered to be 'intermediate', only limited changes have been implemented and there is no attempt to address any wider set of 'tensions' (e.g., oil or water deficits). They provide an opportunity to review the model outputs where comparison of cause-and-effect is clearer. From these intermediate scenarios, more comprehensive scenarios will be developed that seek to address the wider set of tensions and explore how further improvements could be made.

It should also be noted that the scenarios modelled in this paper were developed from the best available data at the time but rely heavily on educated assumptions regarding the nature of technological progress, resource use intensities, consumption patterns and policy pathways. It is also acknowledged that the assumption of all food being supplied domestically is not in line with current trade arrangements and trajectories. Therefore, the scenarios should not be regarded as predictions, but rather explorations of potential futures and the quantitative results should be used as a starting point for further, more nuanced policy development as discussed in Section 6.

\section{Domestic Food Consumption}

\subsection{Methods for Diet Pattern Construction}

The baseline TPWO diet pattern and the two alternative diet patterns were constructed based on varying data and assumptions. Although the TPWO scenario methods and results have been discussed in more detail by Turner et al. [33], they have been included, and in some cases expanded, in this study as a reference against which consumption quantities and resource usage over time relative to that of healthy (alternative) diets could be compared.

In the TPWO scenario, initial consumption quantities were determined using data from the recent National Nutrition and Physical Activity Survey (NNPAS). Food consumption rates were then projected to remain relatively stable or increase marginally for many foods, based on a combination of historical consumption trends and increasing obesity trends.

The alternative diet patterns were developed based on dietary behaviour changes highlighted by Friel et al. [12] as priorities to shift the population's current consumption pattern towards a healthy and sustainable pattern. These are:

(i) avoid consuming beyond energy requirements to reduce the health burden resulting from excessive energy intake and the environmental burden resulting from additional greenhouse gas emissions, non-essential use of natural resources and pressure on biodiversity;

(ii) decrease the consumption of discretionary foods, which typically are energy-dense, nutrient-poor and highly processed and packaged, to reduce both the risk of dietary imbalances and the non-essential use of environmental resources, and

(iii) consume less animal and more plant-derived foods to deliver health and environmental benefits.

An additional behaviour, reducing food waste, has been widely recognised as potentially having a significant environmental impact [15] and as a necessary part of food system sustainability 
assessment [38]. It has been added as a fourth behaviour change for this investigation (referred to hereafter as iv).

These dietary behaviour changes were applied to construct two alternative healthy diet patterns that could be modelled and compared to each other and to the TPWO diet. These diets were:

- Healthy mixed (HM) diet (includes meat, eggs and dairy, dairy components are aggregated);

- Healthy plant-based (HPB) diet (dairy substitute can be generated from cereals, rice or legumes, but is assumed to be legume-based, volume allows for $90 \%$ water content)

Both alternative diets were constructed in accordance with the recommendations of the Australian Dietary Guidelines [42] and specifically with food group serving amounts, variety and balance consistent with those prescribed for different age, gender and lifestage population groups. The breakdown of foods within each alternative diet was determined based on the method established by Larsen et al. [43]. Since it was not feasible to model every food that could belong to each food group, one food was selected from each one to represent that food group. The exception to this was for the meat, fish, poultry, eggs, nuts, legumes and fish group due to the diversity of different foods in this group and that they could be of either plant or animal origin. To account for this diversity, a 'hybrid' serve was constructed for this food group. The weighting was based on the proportion of each of the most consumed foods from within this group as reported in the NNPAS, similar to the approach taken by Ridoutt et al. [32].

It is recognised that the selection of just one food to represent certain food groups is a significant limitation. In other studies that have modelled different dietary patterns, it is not clear how specific foods were chosen, as most present diet profiles based on food groups [32,44]. This dietary guideline 'foundation' approach to developing alternative diet patterns was considered to be the best available approach within given time and resource constraints and considering the objectives of the study. Nutritional adequacy was achieved because dietary guidelines were followed, albeit with a narrow variety of foods, and dietary behaviour changes related to avoiding overconsumption (i) and reducing consumption of discretionary foods (ii) above could be enacted. The particular food chosen to represent the fruit, vegetable, grains and rice food groups would not result in any difference in calculation of environmental impacts because each food in each food group is assumed to have the same impact within a given food group.

For each alternative healthy diet per capita consumption does not increase over time as it does in TPWO. Dietary behaviour change (iii) then became the point of difference between the two alternate diets. Whereas the HM diet satisfied two of the three priority behaviour changes, the HPB diet satisfied all three priority behaviour changes. Much of the criticism of the EAT Lancet diet centred around the low levels of meat products. By modelling two alternative diets, one with animal products and one without, and comparing them to the current diet, it is possible to explore differences in environmental pressures between healthy and unhealthy omnivore diets, and healthy diets with or without animal products.

When modelled, the shift from the average diet to each healthy diet was phased in over 10 years, from 2025 to 2035. In this time waste from food consumption (i.e., household and retail food waste) was assumed to reduce by $50 \%$, thus satisfying (iv) and in line with SDG target 12.3 . This target is ambitious but is supported by results from on-ground projects in Melbourne [45].

\subsection{Results: Consumption Overall and by Food Type}

Figure 1a shows the average amount of food eaten per person per day for different food groups according to the diet profiles of the current TPWO diet and the two alternative healthy diets. These figures do not include food waste which would add an extra $50 \%$ to overall per capita consumption in the TPWO diet scenario and $25 \%$ to overall consumption in both of the healthy diet scenarios (with varying percentages across each food group). 


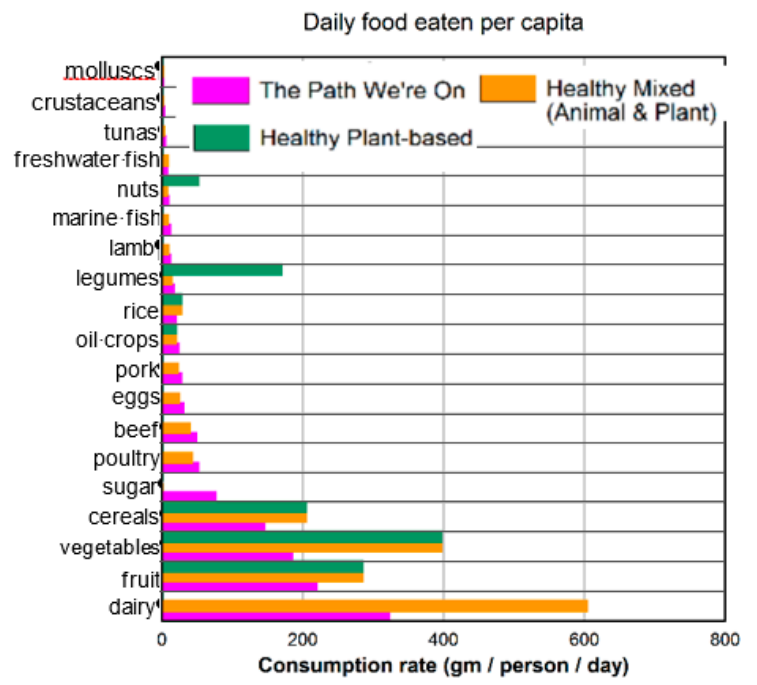

(a)

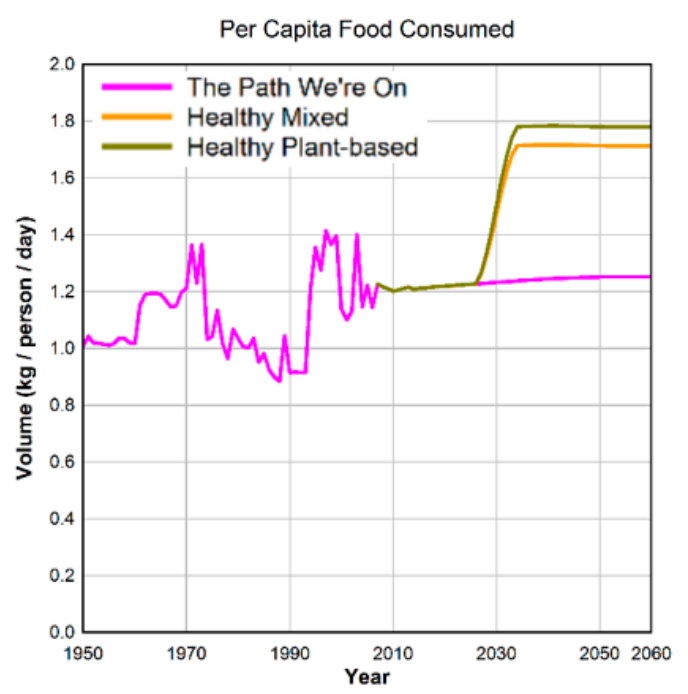

(b)

Figure 1. (a) Food eaten per capita, by the Australian Stocks and Flows Framework (ASFF) food types, for 'The Path We're On' (TPWO) scenario (based on current consumption data), and the alternative healthy diets (healthy mixed (HM) or healthy plant-based (HPB)). (Note: The water component of dairy substitutes (e.g., soy drinks) is excluded in consumption of legumes in the HPB diet). (b) Aggregate food consumed per capita. (For comparison of totals, the HPB diet total consumption includes water incorporated in dairy substitutes).

Substantial changes are evident between the diet patterns. The TPWO diet profile is clearly high in sugar consumption, it is the fifth highest category and the amount is higher than any of the protein food types, while both healthy diet profiles have significantly higher vegetable, fruit and cereal proportions. Even though most food types showed minor increases in consumption rates over the scenario period for the TPWO diet pattern (though there are declines in rice, fruit, beef and eggs) [33], the higher requirements of vegetables, fruits, nuts, cereals, and dairy (or grain equivalent meant that the total food consumed in the healthy diets per capita is higher than TPWO diet (Figure 1b).

Overall consumption of food by volume, from the combination of population multiplied by food consumed per capita, grows in TPWO and the alternative diets scenarios (Figure 2). In the two healthy diets, overall consumption exceeds consumption in TPWO. Although the difference between the healthy diets and TPWO is reduced if consumption wastage is halved, overall consumption remains higher. Evidently, population growth (moderate and identical across these scenarios) drives longer-term growth in overall consumption volumes.

While aggregate food consumption is similar across the scenarios, there are substantial differences in consumption volumes of crop and livestock products (Figure 3). In particular, the volume of vegetables required approximately doubles in both healthy diet patterns compared with TPWO. In the HM diet, the volume of dairy required is increased by almost $100 \%$, while the HPB diet results in a ten-fold increase in legume volume. 


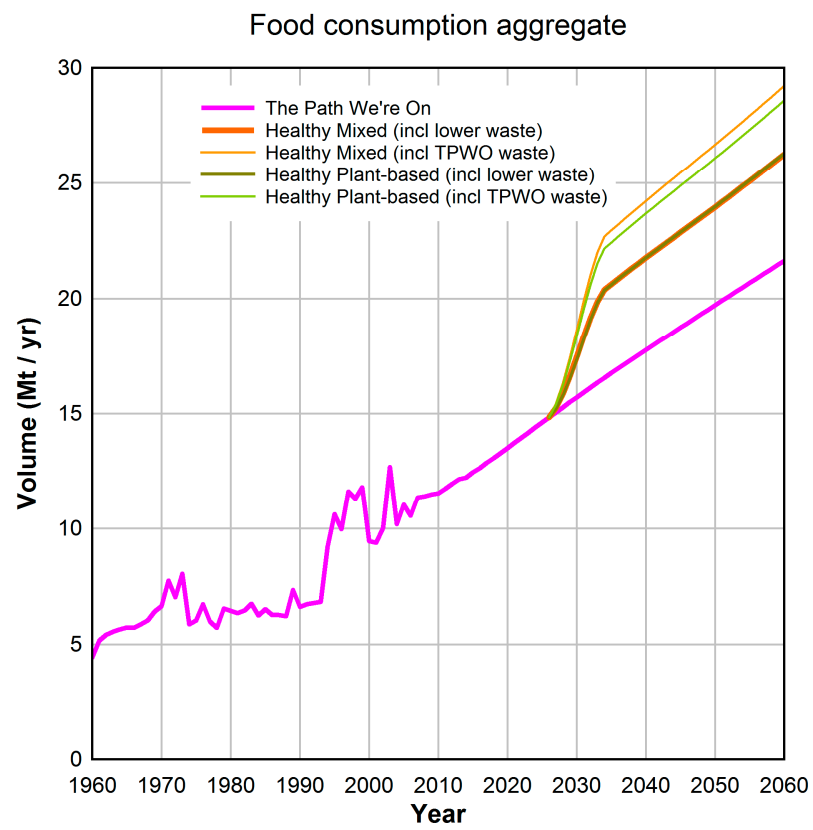

Figure 2. Total food consumed by the Australian population, comparing TPWO with the two alternative healthy diets, and incorporating waste in consumption. (The HPB diet includes water incorporated in dairy substitutes). Wastage in consumption was reduced in both the HPB and HM diets, with higher consumption shown if the background (TPWO) rate of waste is applied.
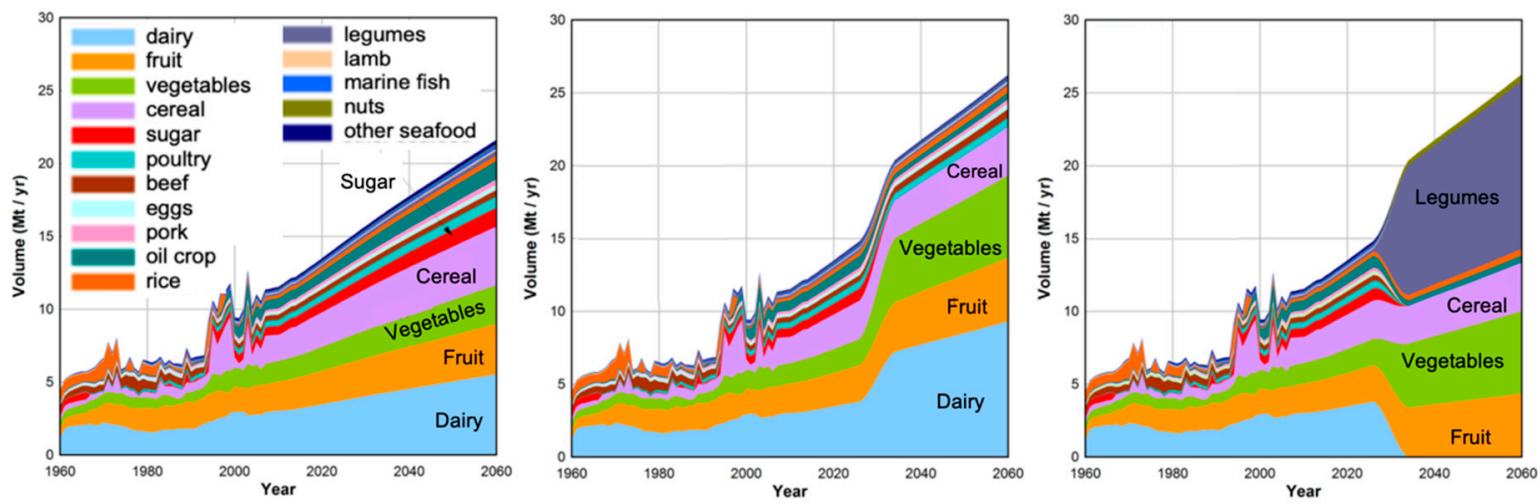

Figure 3. Breakdown of the volume of food consumed by the ASFF food types, stacked (or cumulative), for the (a) The Path We're On scenario, and the alternative healthy diets based on (b) crop and animal products, and (c) crop products only.

\section{Direct Food Availability and Food Trade: Net Imports Relative to Production}

To enable the comparison of environmental impacts and resource costs of producing these diets, the authors first tested whether the full dietary requirements could be met within Australia, while also identifying where future export or import tensions might arise. This was done by re-allocating productive areas from food types in surplus to domestic requirements to address deficits in others, with the aim to achieve 'direct food availability'.

\subsection{Method}

Once the new diets were applied, crop areas and livestock numbers were re-allocated in both scenarios with the objective of ensuring that production at least satisfies domestic consumption (effectively minimising net imports). Land was only re-allocated to meet domestic needs, not to reduce 
production to a required level. For example, if land was not needed for legume production, it keeps producing beef and that beef is exported. The actual production of a particular food type is only reduced if it is in excess and this enables land to be reallocated for use for other crop or animal products that are in deficit (i.e., consumption higher than production, or imports greater than exports).

Any reallocation of land is constrained to occur in each Statistical Division (SD) (A Statistical Division (SD) is an Australian Standard Geographical Classification (ASGC) defined area which represents a large, general purpose, regional type geographic area. SDs represent relatively homogeneous regions characterised by identifiable social and economic links between the inhabitants and between the economic units within the region, under the unifying influence of one or more major towns or cities. They consist of one or more statistical subdivisions (SSDs) and cover, in aggregate, the whole of Australia without gaps or overlaps. They do not cross State or Territory boundaries and are the largest statistical building blocks of States and Territories. http://www.abs.gov.au/websitedbs/D3110124.NSF/f5c7b8fb229cf017ca256973001fecec/ 53bbe9630b24d6f4ca256c3a000475b8!OpenDocument\#Statistical\%20Division\%20(SD)) rather than on national totals, to simulate increased production of particular crops being located in regions that are likely suited to the production of that crop. Table A1 in the Appendix A describes the process used to reallocate land for these intermediate scenarios, with a general description of the logic/assumptions underlying each step and outlines how changes to specific input variables were made.

\subsubsection{Cropping Activity}

The TPWO scenario sees an initial increase in total cropping activity (Figure 4a,b) up to 2050. This is primarily due to the fact that crop yields per hectare decrease over time due to the combined effects of climate change and land degradation [33]. Cropping activity for animal feed (sown pasture, hay, silage), cereals, sugar, legumes, fruit and vegetables reach constant values from 2050 onwards. This is due to agricultural land expansion reaching limits in each SD where the specific cropping activity is occurring, which has implications for direct food availability and export capability (see Section 4.2.1).

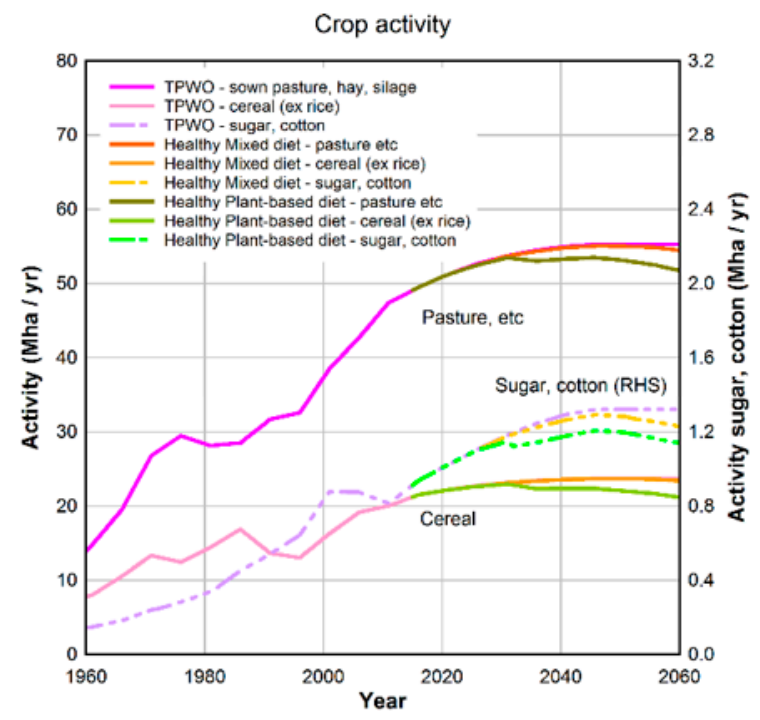

(a)

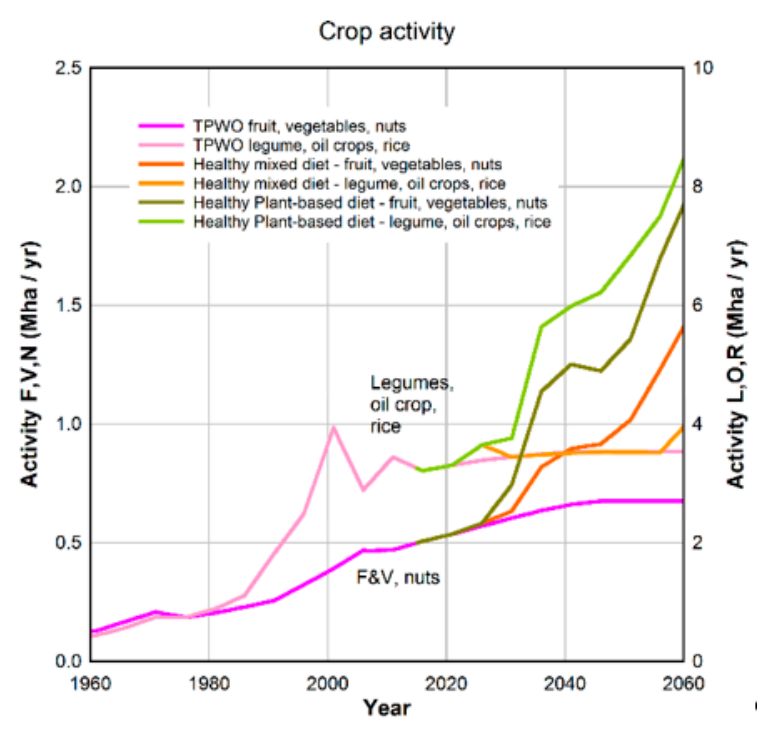

(b)

Figure 4. Cropping activity for (a) crops that are displaced, and (b) crops that expand in the alternative diets.

An increase in cropping activity also occurs in the alternative diet scenarios, however, the land reallocation causes the total area to be split across crops differently as seen in Figure 4. For both healthy diets, there are area decreases in sugar cane, cereals (excluding rice) and sown pasture (the decrease is 
more significant in the HPB diet scenario compared to the HM diet scenario). This is important because it makes land suitable for cropping available to produce other crops such as fruit and vegetables without reaching land availability limits. Substantial increases occur in cropping activity for fruit and vegetables in both healthy diets, and in legumes and nuts in the HPB diet scenario. This is partly due to increases in domestic consumption but also due to significant decreases in crop yields per hectare (see [33] for more detail) as a result of runaway decreases in landscape function (i.e., land degradation) after 2050 and climate impacts (despite modelled genetic improvements).

In some cases (e.g., nuts, vegetables and fruit in both healthy diets, and legume grain in the HPB diet), land reallocation is unable to occur to meet domestic requirements. This is because the reallocation is constrained to occur in each SD. Where suitable regions have insufficient extant cropland for the calculated reallocation to occur, the national production of crops is still less than domestic consumption. This is more pronounced in the early stages when the rate of diet change is greater than the rate of land re-allocation but reduces over time to a steady amount as more land is re-allocated.

\subsubsection{Livestock Numbers}

Some livestock numbers, aggregated over Statistical Divisions to national totals (Figure 5), change significantly following reallocation of crop and livestock production. Beef and sheep numbers are less than TPWO in both alternative diets, to allow for sufficient production of other food types to achieve direct food availability. Poultry numbers (aggregated over meat and egg birds) do increase, but not significantly between scenarios (nb: Volatility in some of the scenario numbers results from a change in crop production (for feed) due to randomness imposed for climate variation, see [33] for more details).

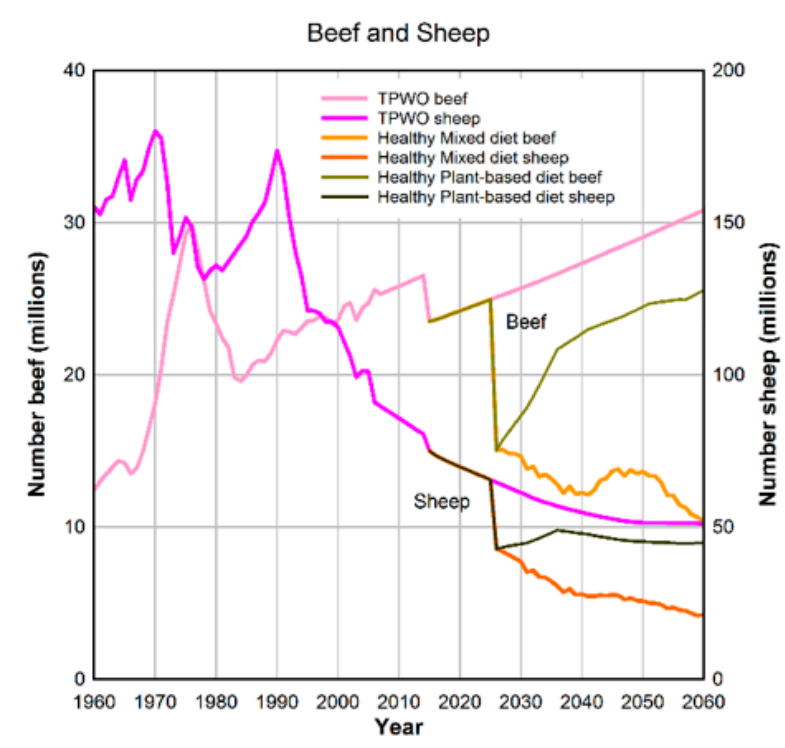

(a)

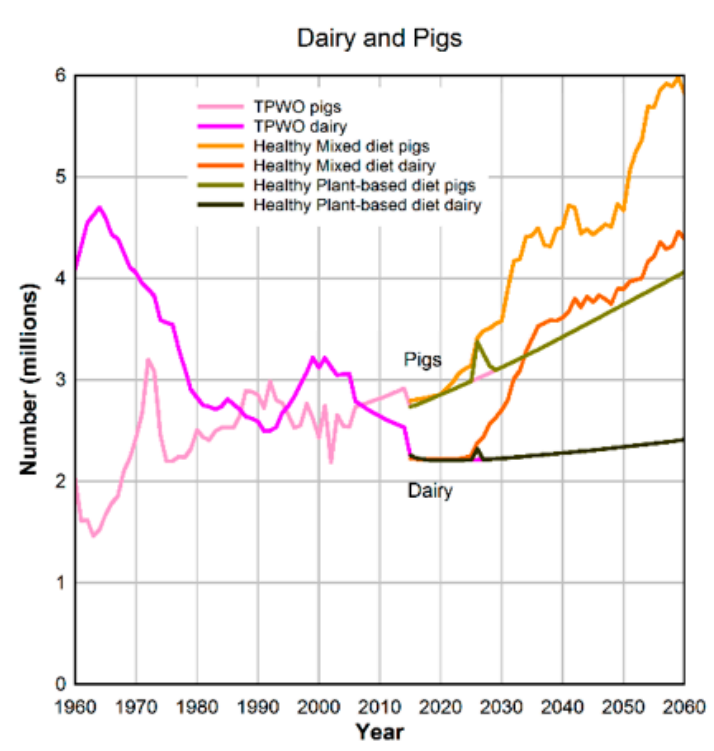

(b)

Figure 5. Selected livestock numbers for TPWO and alternative diet scenarios. (a) Beef and sheep, (b) dairy and pigs.

In the HM diet, both pig and dairy numbers rise to meet domestic consumption of pork and dairy products. The head of dairy cattle increases substantially, reversing the historical downward trend. The increase in pig numbers over the longer term is high but not out of keeping with the historical development. Due to the higher feed requirement of pigs and dairy, the decrease of beef and sheep numbers exceeds the change in dairy and pig stock.

The HPB diet also results in lower beef and sheep numbers compared with TPWO (but not zero, because although meat is not consumed in this scenario, it is assumed it is still produced for export). The initial reduction occurs because the increase in crop production needed to supply plant-based foods 
was obtained through sacrifice of sown pasture (for beef and sheep grazing, with dairy quarantined), after having attempted to re-allocate cropping activities within regions. The cattle numbers in the HPB diet then rise again because beef production continues to follow the upward historical trend in the model. The reduction of beef and sheep numbers in the HM diet is greater than the HPB diet because of the need to supply dairy products (as well as pork and poultry), which place comparatively higher demands on crops for feed and consequently require a greater sacrifice of sown pasture used for beef and sheep, (i.e., in the HPB diet, not having to feed livestock in order to produce dairy, eggs and meat for domestic consumption, relieves pressure on cropland area and therefore allows more beef and sheep grazing for export). For the HPB diet other livestock numbers, such as dairy and pigs, are lower than the HM diet, illustrating a trade-off between types of livestock. For these stock, the HPB diet follows TPWO trajectory since no adjustment is made because no imports are required to satisfy domestic food consumption in this diet.

\subsection{Results}

The metric used here to represent direct food availability is 'net imports relative to production'. Net imports are imports less exports, and these are positive if imports are greater than exports (lack of direct food availability) and negative if exports are greater than imports (direct food availability). Expressing these relative to production volume gives a measure of how much production would have to change to address food availability, and it allows multiple food types to be easily compared. In the graphs that make up Figure 6, above the line means consumption exceeds production and direct food availability is not achieved, while below the line means that production exceeds consumption and direct food availability is achieved. Figure 6 shows how the limits on overall cropping activity shown above will impact on domestic food availability, but also how domestic consumption patterns contribute to improving or worsening the situation.

Note, for seafood, the magnitude of the import requirement was generally so high that the relative net import figures have been scaled down (by factors of 100 and 10) to show the data on a common scale.

\subsubsection{The Path $W^{\prime}$ re On}

In TPWO, many food crops display existing and/or increasing import reliance. This is more evident on the 2060 timeframe compared with the 2040 horizon reported in the analysis of TPWO [33]. The results show that Australia is already reliant on imports for nuts and oil crops and look to be reliant on imports of fruit by 2040 and rice and vegetables by 2055, with legumes and sugar likely to shift into the import reliance category not long afterwards. Sharp turning points towards import reliance for many of the abovementioned crops coincide with land availability limits being reached across different cropping categories around 2050 (Figure 4). Without the possibility to bring more land under cultivation, the trend moves very quickly towards import reliance. This acceleration is caused by the combination of population increase, per capita consumption increases, and crop yield decreases due to climate change impacts and land degradation. The previous study by Turner et al. [33] showed that land degradation increases over time from $11 \%$ in 2020 to $17 \%$ by 2040 .

Pork and dairy develop significant import reliance, with poultry and eggs following. This is driven by increases in domestic consumption due to a combination of population growth and marginal increases in per capita consumption. Seafood is absolutely insecure, Australia is completely reliant on imports for seafood. 

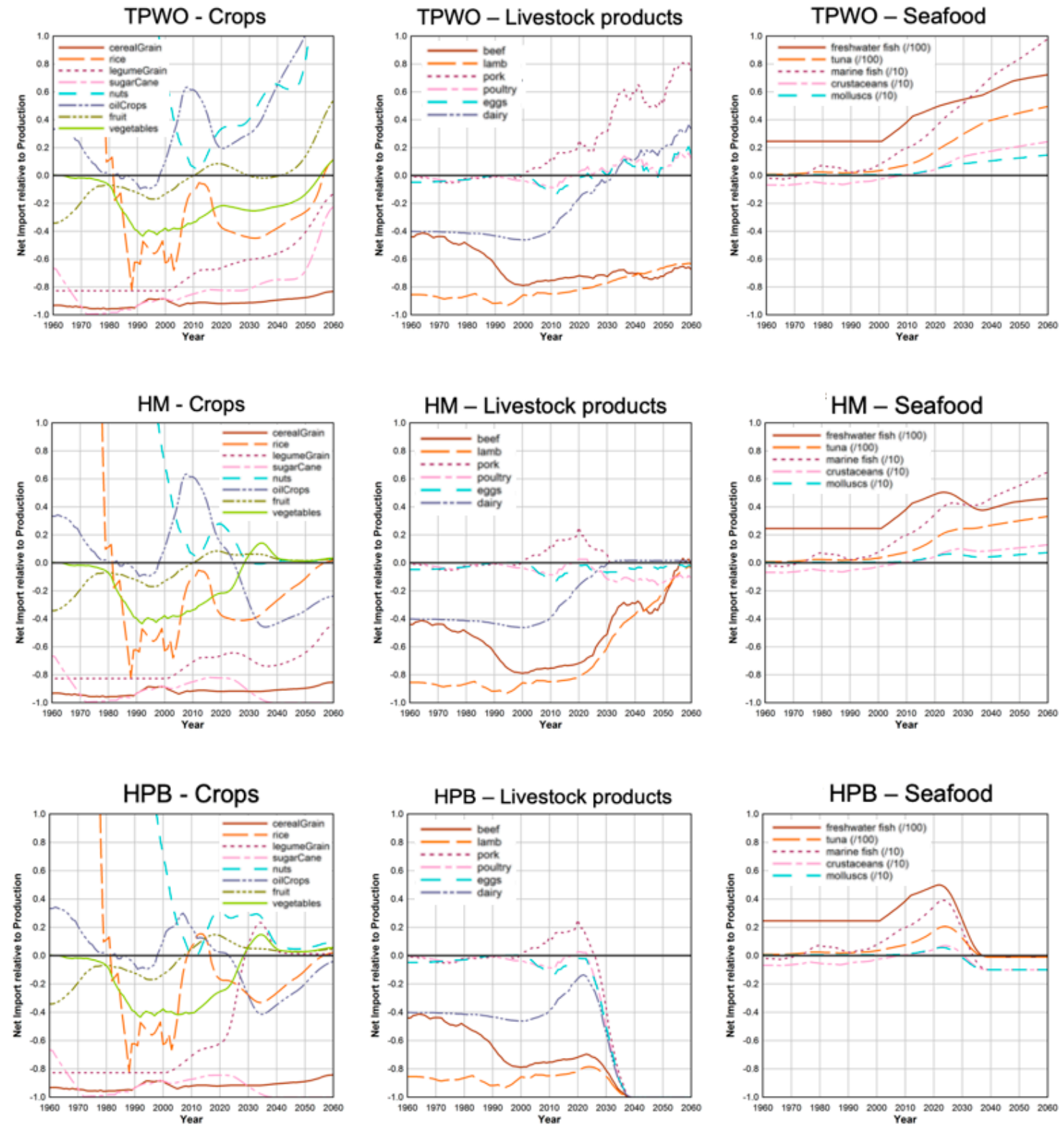

Figure 6. Net imports relative to production of all food types and for scenario comparison. Positive net imports are an indicator of direct food insecurity.

\subsubsection{Healthy mixed diet}

This scenario effectively achieves direct food availability for crop and livestock products. Minor decreases in cropping activity of broadacre crops make it possible to produce other crops necessary for a healthy diet such as fruit and vegetables. The net situation diminishes over time, however, particularly for livestock products. Competition for diminishing sources of animal feed means that domestic consumption needs equal the number of animals that can be supported by 2060. Seafood remains heavily import reliant, but at slightly lower levels than TPWO due to a lower wastage factor.

\subsubsection{Healthy Plant-based Diet}

This scenario effectively achieves direct food security in all food types, largely by avoiding any consumption of livestock products or seafood and maintains significant export capabilities. 


\section{Environmental Pressures of Different Diets}

In this section, we report a number of simulated environmental pressures such as water, land, fuel and fertiliser use, as well as GHG emissions, for the alternative diet scenarios compared with TPWO. The outcomes presented include those that are directly attributable to domestic food consumption (e.g., the water used in agriculture if production exactly matched domestic consumption) and those that are attributable to overall domestic agricultural production, including food produced for export. These results are also compared to those for the whole economy to provide important context for the changes achieved.

This section does not include a discussion of fish stocks. Although sustainable and resilient supplies of fish and seafood are essential for a healthy diet, the fishing industry has little or no demand for resources such as land, water, fuel and fertiliser compared to the production of other foods. As shown in Section 4.2.1 and Figure 6, Australia is also largely dependent on imported seafood, the environmental impacts of which are considered to be outside the scope of this paper.

\subsection{Method}

The core model of the ASFF calculates the resources used by commodity for the agricultural sector, including those required to produce exports, so the figures for overall agricultural production could be extracted directly. To calculate the resources required to meet domestic food consumption, however, it was necessary to determine the proportion of agricultural production that is consumed as food by the population and the subsequent proportion of overall resources required. This was done by determining a domestic consumption factor.

For each diet, the food consumption per capita for each food type was determined according to the diet profiles shown in Figure 1a. These were then multiplied by the national population to get total domestic food consumption (Figure 3). For each food type within each diet, the total domestic consumption was divided by the total production to determine the domestic consumption factor. This factor was then multiplied by the total resource use for each food type to determine the proportion attributable to domestic consumption.

Both processes (for domestic consumption and agricultural production) calculate the resources required and emissions generated to produce food (including livestock farming, livestock feed and crops), as well as the emissions produced from the disposal of food waste. It does not include the resources used in other parts of the food system such as food processing, distribution and household preparation. Water figures also take into account only irrigation water that is used to grow crops and animal feed as well as drinking water for animals, commonly referred to as 'blue' water. 'Green' water, the water that falls directly onto crops as rain, is not included because it is not tracked in Australia's water accounts.

\subsection{Results}

\subsubsection{Water Use for Domestic Consumption for Different Diets}

Water use directly attributed to food consumption is consistently lowest in the TPWO scenario and highest in the HM diet (Figure 7a). 

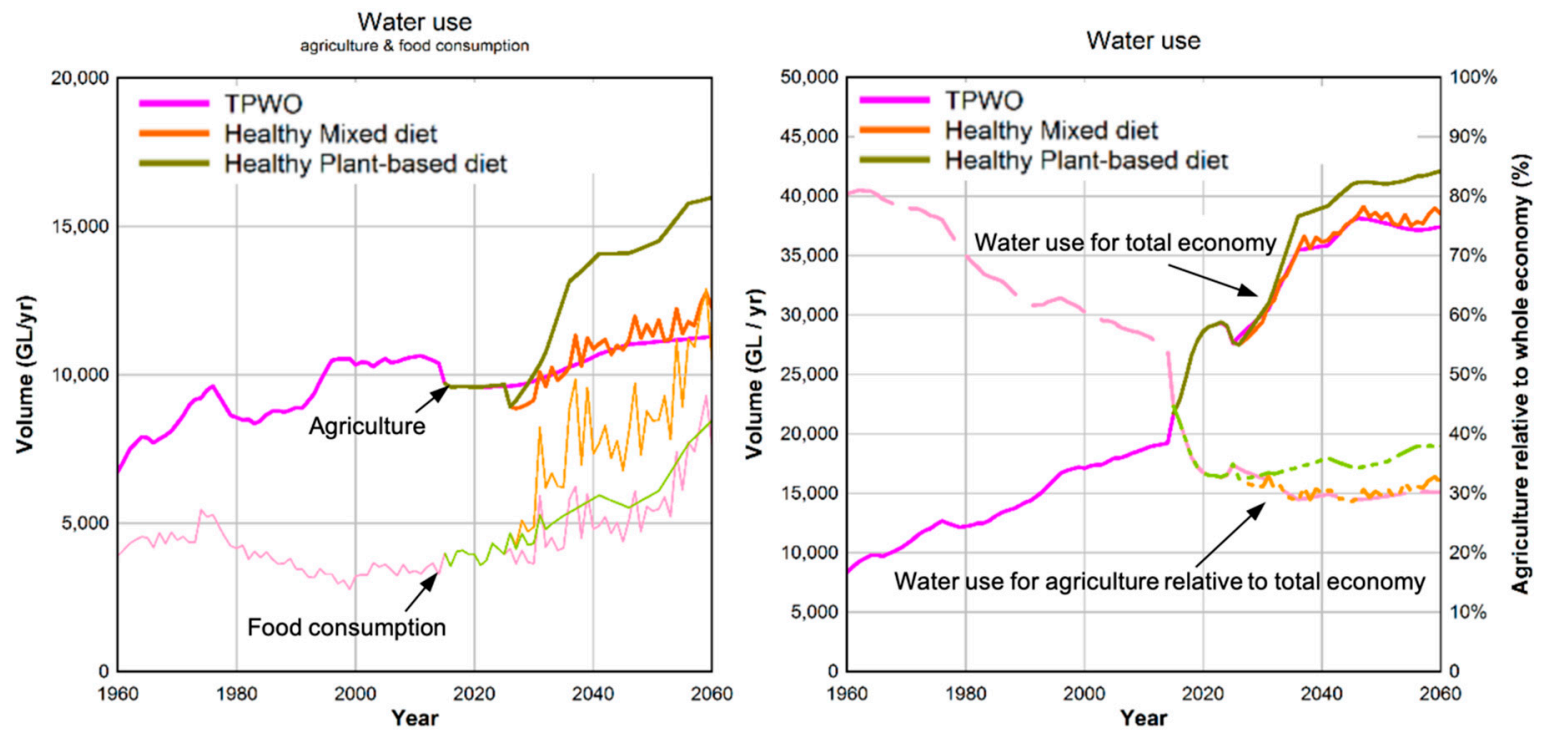

Figure 7. Water use for different diet scenarios for (a) domestic food consumption and agriculture and (b) across the entire economy.

Figure 8 shows that the HM diet scenario has the highest water use. This can be attributed to increased beef and dairy consumption but is a result of dynamics related to per capita consumption trends, population increases and climate change impacts. Per capita consumption of beef begins as higher in the TPWO diet compared to the HM diet (see Figure 1a) but decreases over time according to historical trends in ASFF (see Figure 4 in [33]). This is in line with population data that indicates a reduction in beef consumption and an increase in consumption of chicken and seafood since the 1970s [46]. Data from the most recent national nutrition survey indicate that in Australia, chicken continues to be consumed more commonly than beef [34]. This moderates the overall increase in beef consumption due to a higher population and leads to total beef consumption in the TPWO diet being less than in the HM diet, where the per capita consumption remains constant.
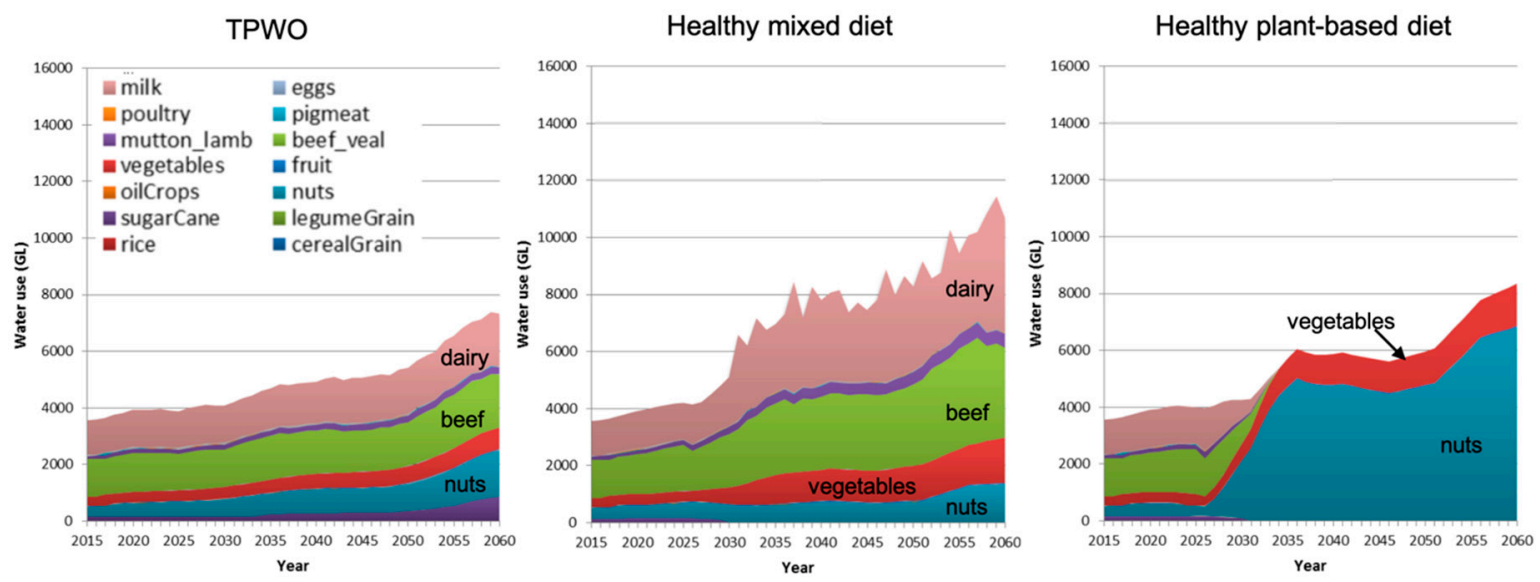

Figure 8. Water use for domestic food consumption by food type for (a) TPWO scenario; (b) healthy mixed diet scenario and (c) healthy plant-based diet scenario.

Dairy and vegetable consumption are almost double in the HM diet compared to the TPWO. These combined account for the rest of the extra water required for the HM diet.

Although the HPB diet has no beef and dairy, the overall water use is higher than TPWO because of the high proportion of water-intensive foods such as nuts and vegetables. To ensure nutritional adequacy, the HPB diet also contained a high proportion of legumes (as plant-based alternatives to 
meat and dairy). Compared to other vegetables and nuts, legumes are less water-intensive to produce and therefore, do not feature in Figure 8c.

\subsubsection{Water Use for Agricultural Production for Different Diet Scenarios}

The healthy plant-based (HPB) diet scenario produces the highest water use by agriculture and across the whole economy (Figure 7a,b). This high water use is a result of a doubling in crop irrigation, more than offsetting a small drop in water due to a reduction in domestic consumption of livestock products (Figure 9c). The water used in production above that attributed to consumption is effectively embodied in exports (nb: There are also relatively minor differences in water use across the scenarios in food processing and recycling.) It is clear in Figure $9 \mathrm{c}$ that the increased water use for crop irrigation in the HPB diet compared to TPWO (Figure 9a) is primarily attributed to the production of nuts to satisfy protein requirements for domestic consumption.
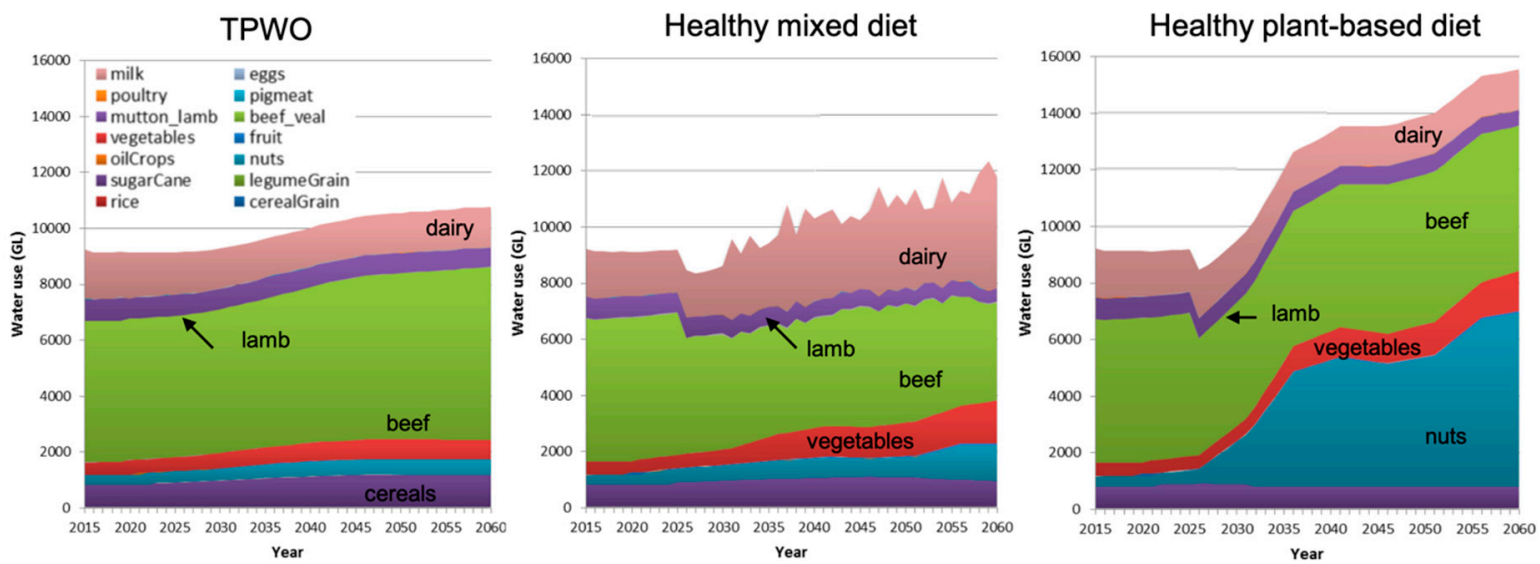

Figure 9. Water use by food type based on domestic production for different diet scenarios (a) The Path We're On, (b) healthy mixed diet, (c) healthy-plant-based diet.

The healthy mixed (HM) diet results in marginally higher agricultural water use compared to TPWO (Figure 7a). Over time, water use associated with food consumption for this diet trends towards the total agricultural water use, because as the population increases, food production becomes increasingly dedicated to meeting domestic needs with little left for export.

The additional water use in the HM diet (above that of the TPWO diet) is due to dairy and vegetable production (Figure $9 \mathrm{~b}$ ). The increase in water use for these two food types is driven by higher per capita consumption domestically, amplified by increases in water-use intensities for production due to climate change impacts implemented across all scenarios.

Overall, both healthy diet scenarios require more water for domestic consumption and production compared to the TPWO scenario, so they could be considered less sustainable in terms of water use. However, although water use for agriculture accounts for between $30-40 \%$ of the total water use across the economy, the maximum difference in water use between the HM diet and the HPB diet scenarios compared to the TPWO diet for consumption and production is less than $10 \%$ of total water use across the economy.

\subsubsection{Land Use for Domestic Consumption across Different Diets}

The HPB diet has the lowest land use for domestic consumption and the HM diet has the highest over the long term by a significant margin (Figure 10). The TPWO diet uses approximately $75 \%$ of the land used in the HM scenario. 

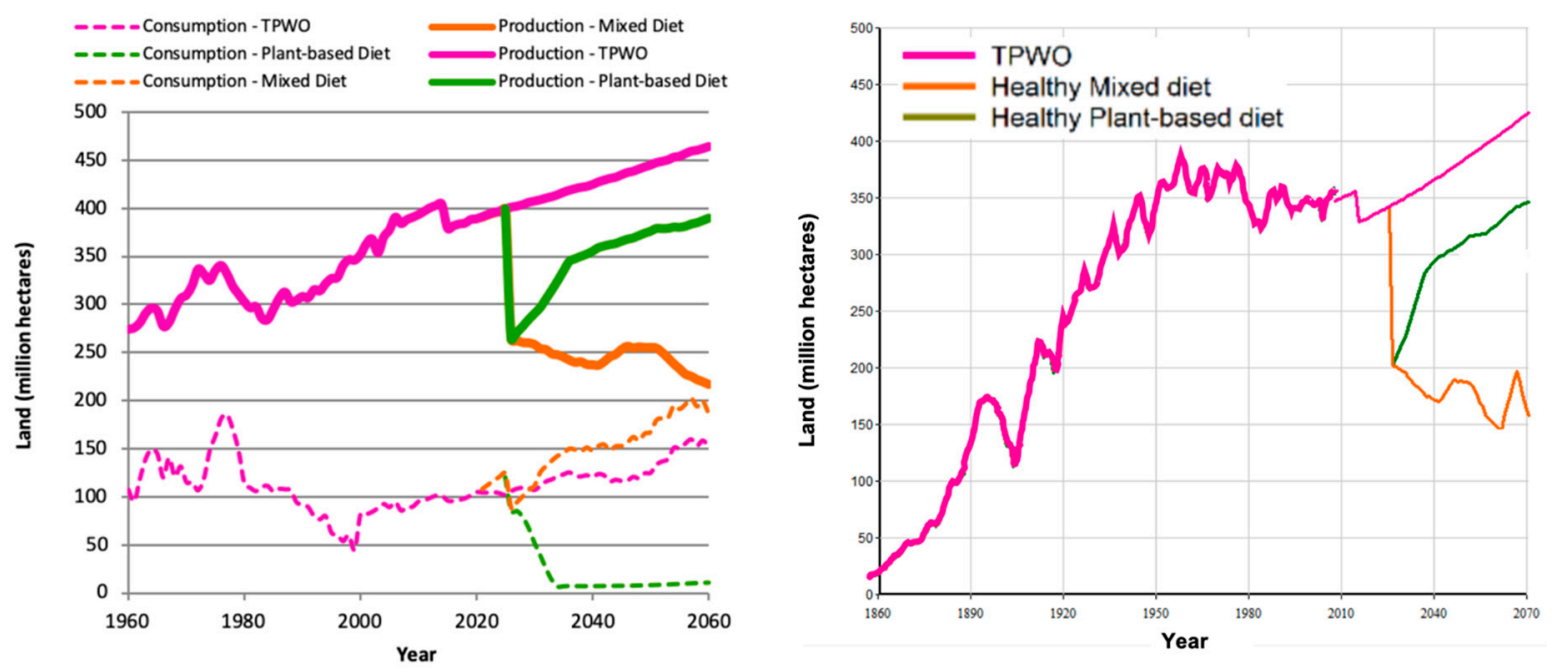

Figure 10. Land use for different diet scenarios for (a) domestic food consumption and total agricultural production, and (b) native pastureland.

The significantly lower land use in the HPB diet scenario is due to the lack of beef consumption, which dominates the overall land use for the other diets $(+75 \%)$ due to the extensive farming methods practiced in Australia (Figure 11). Likewise, land use for the HM diet is higher than the TPWO diet due to higher beef consumption (see Section 5.2.1 for further explanation).
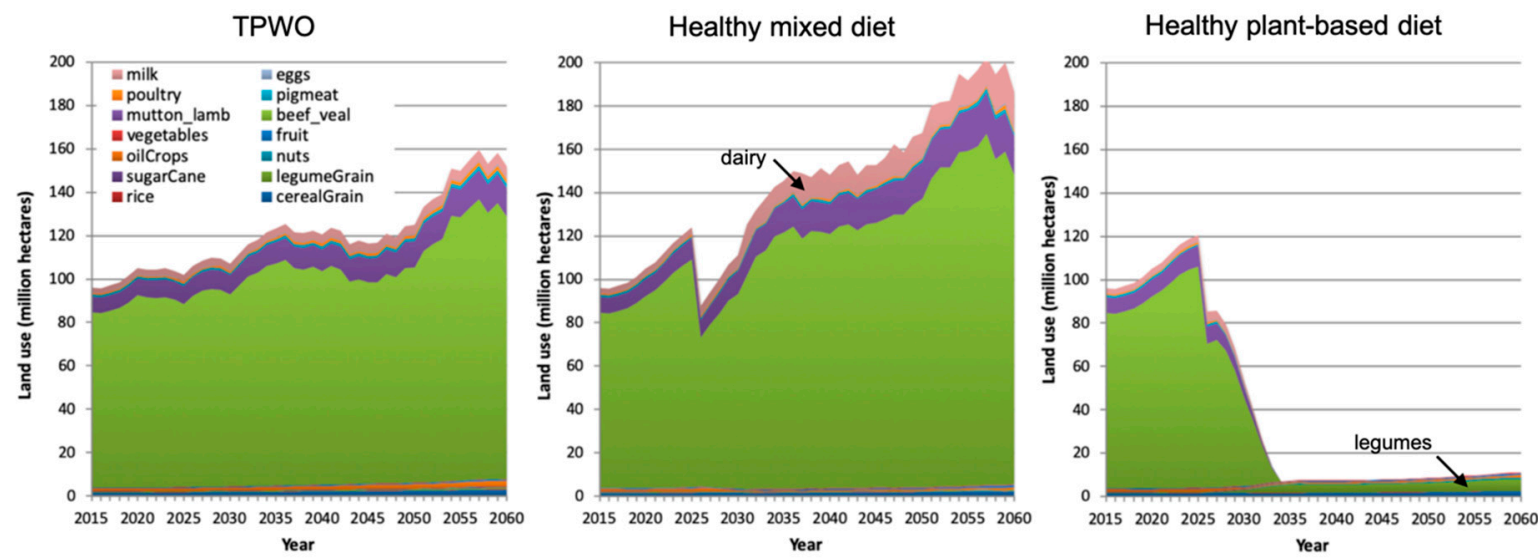

Figure 11. Land use by food type for domestic consumption for different diet scenarios for (a) The Path We're On, (b) healthy mixed diet, (c) healthy plant-based diet.

Figure 10b shows a significant 'freeing up' of native pasture land for agricultural production overall in the HM diet scenario. This is because the feed requirements for pigs and chickens (to meet direct food availability requirements, explained in Section 4.2.1) reduce the number of cattle and sheep that can be supported. In Australia, beef cattle are initially raised on native pasture but then 'grain finished'. If there is not sufficient grain available for this to happen, cattle are effectively removed from native pastureland within the model. Since this land is marginal and only suitable for extensive grazing, it cannot be re-allocated for other forms of agriculture so remains unused in the HM diet scenario. Similar to the results for water use, land use associated with food consumption for this diet trends towards the total agricultural land use (Figure 9a), because as the population increases, food production becomes increasingly dedicated to meeting domestic consumption needs with little left for export. 


\subsubsection{Land Use for Agricultural Production for Different Diet Scenarios}

Although land use drops initially for each healthy diet scenario when different diets are introduced, the overall agricultural land use then diverges significantly. As discussed in Section 5.2.3 and shown in Figure 10a, agricultural land use for the HM diet scenario decreases due to competing demands for animal feed and fewer cattle and sheep being able to be supported. Land use for the HPB diet does the opposite and increases over time. Figure $12 b, c$ shows that the difference in land use between the HM and HPB diet scenarios is primarily due to beef production. Having a plant-based domestic diet eliminates the necessity to feed pigs and chickens to meet direct food availability requirements, so more cattle and sheep can be farmed for export and land use rises.
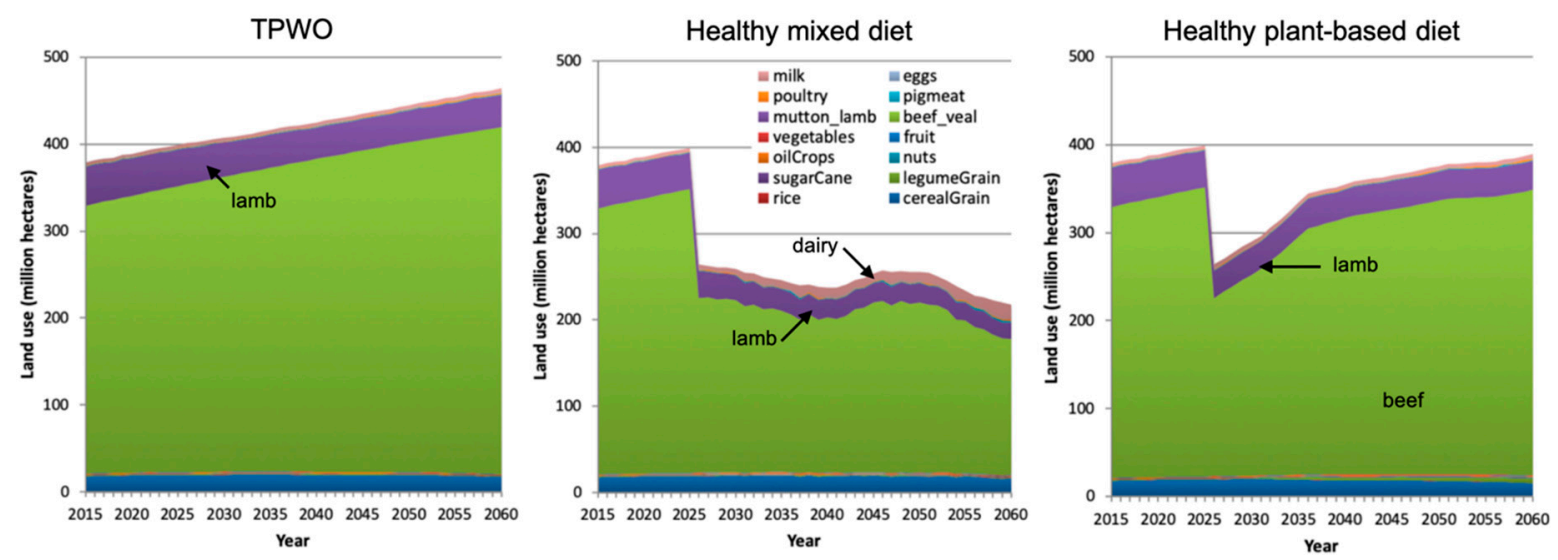

Figure 12. Land use by food type based on domestic agricultural production for different diet scenarios (a) The Path We're On, (b) healthy mixed diet, (c) healthy plant-based diet.

However, the number of cattle and sheep that could be supported in the HPB scenario will always be less than in the TPWO scenario. Some cropland used to produce animal feed in the TPWO scenario is diverted to produce food for human consumption to meet higher plant-based food requirements in the HPB diet scenario. Similar to the decrease in land use for the HM diet scenario (but to a lesser extent), this results in a reduction in overall agricultural land use because less cattle and sheep can be supported and less native pasture area is required (Figure 10b) (see Section 5.2.3 for more detailed explanation).

Although land condition in different regions does differ somewhat between the scenarios, the national average yield loss due to degradation is effectively the same irrespective of the scenario. This reflects that the majority of the cropping activities (cereals and sown pasture) are similar across the scenarios (Figure 12) and that no regenerative practices have been implemented.

As stated in Section 2, the impacts of climate change are also common across all scenarios. This is particularly important when looking at livestock production due to its dominance of agricultural land use. Temperature rises increase heat stress on livestock so more land will be required to raise the same number of animals. This increased land use intensity amplifies existing increases in production required to meet consumption needs of a larger population.

\subsubsection{Greenhouse Gas Emissions for Domestic Consumption Across Different Diets}

Figure 13a shows that the HM diet generates higher emissions over time compared to the TPWO diet, while the HPB diet generates less than TPWO for domestic food consumption. 

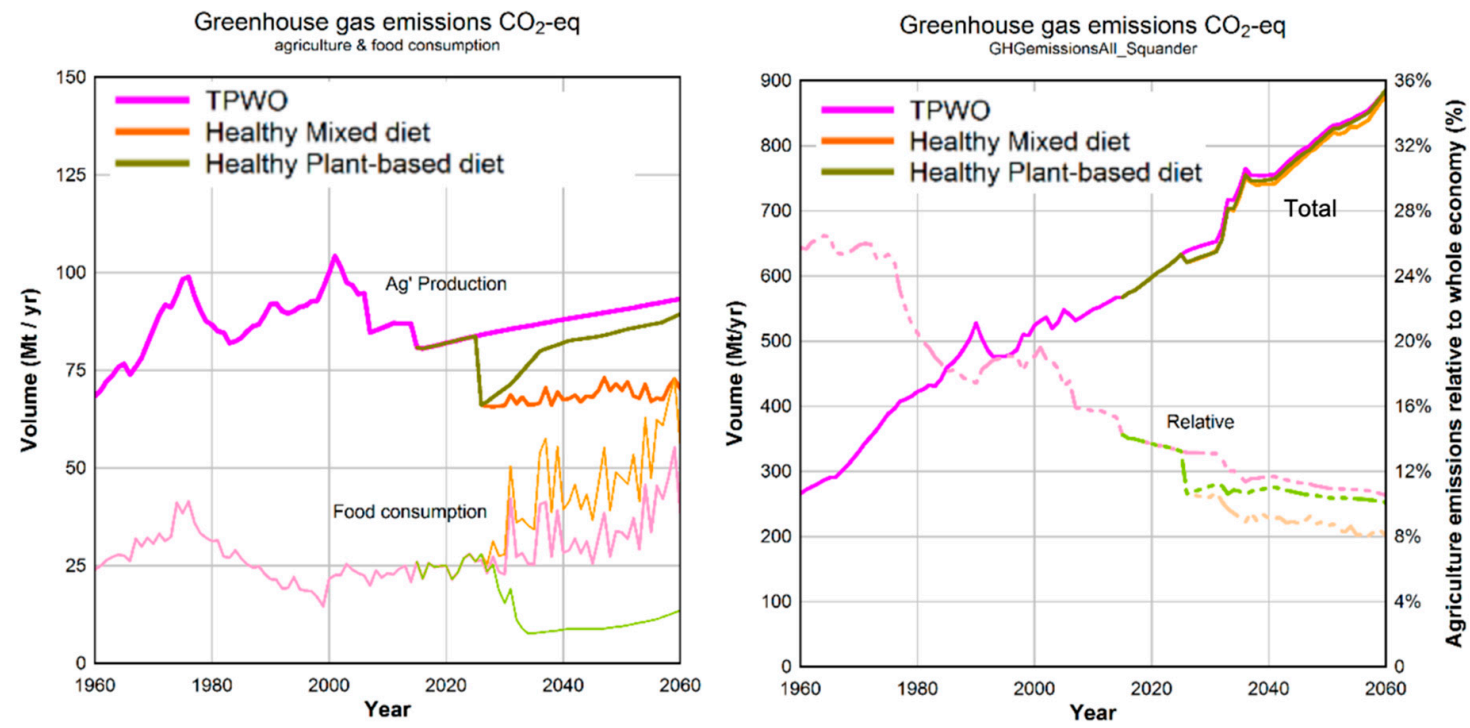

Figure 13. Greenhouse gas emissions from (a) total agricultural production and food produced for domestic consumption, and (b) total emissions across the economy, with agricultural share on right hand side.

Emissions from agriculture are overwhelming dominated by process emissions (i.e., methane emissions associated with enteric fermentation from ruminant livestock and nitrous oxide emissions from cropping) compared with those attributed to fuel consumption. The process-based emissions arise mostly from livestock and this largely explains the differences between the scenarios (Figure 14). Consequently, emissions directly attributable to domestic food consumption are highest in the HM followed by TPWO due to beef and dairy consumption and substantially less in the HPB diet scenario.
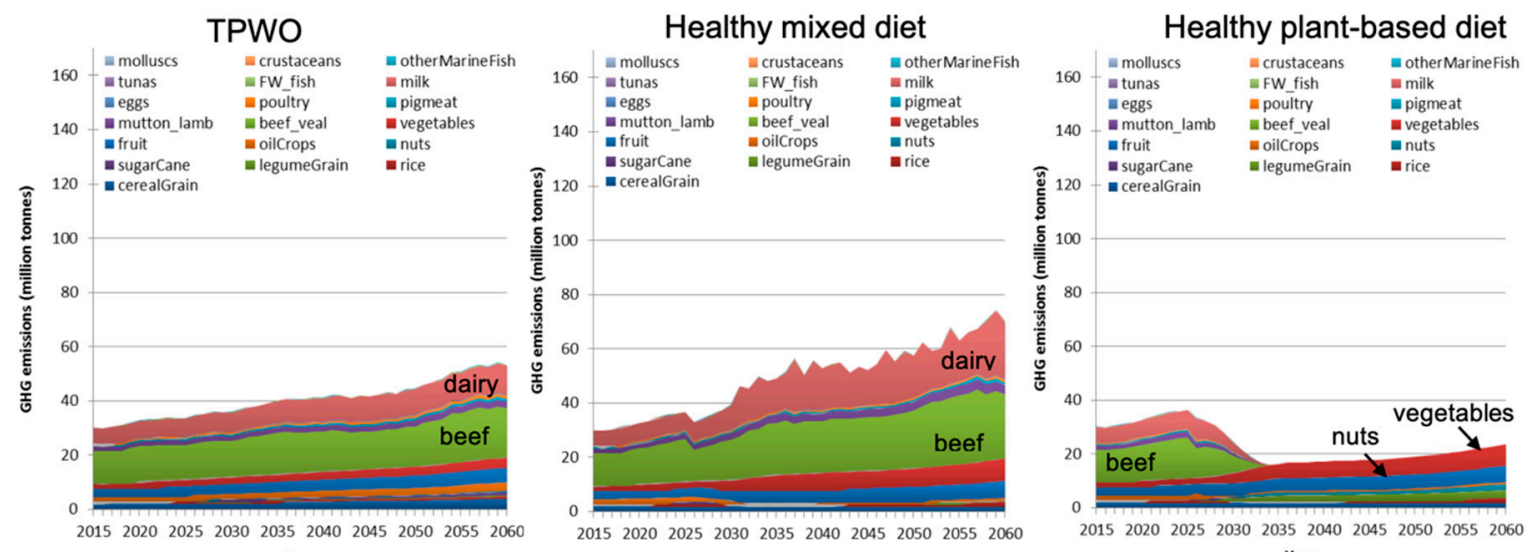

$$
\text { Year }
$$

Figure 14. Greenhouse gas emissions by food type for different diets based on domestic consumption (a) The Path We're On, (b) healthy mixed diet, (c) healthy plant-based diet. 
Based on the straight comparison of embodied emissions of different food types, these results do not support the assumption that healthy diets are more sustainable diets in the Australian context if the healthy diet includes livestock products. However, if the marginal land no longer used for extensive grazing in the HM and HPB diets were to be repurposed for forestry to create carbon sinks, for example, it may have a more favourable impact on emissions for the healthy diets. Likewise, if methane emissions from cattle could be reduced or nitrous oxide emissions managed better. Although efforts are being made to address these issues in agricultural research, exploration of these kinds in interventions, however, is outside the scope of this study.

\subsubsection{Greenhouse Gas Emissions from agricultural production for different diet scenarios}

The alternative healthy diet scenarios show an initial drop in GHGE (CO2-eq) from agriculture, but then all scenarios produce growth in emissions over time (Figure 13a). There are significant differences between the scenarios, with the HM diet scenario leading to the lowest volume, and the HPB diet producing somewhat less than TPWO.

GHGE trends for agricultural production in Figure 15 show that ruminant-based livestock farming (cattle and sheep) makes a significant contribution to the total amount. Different percentages from each type of ruminant farming occur across the scenarios depending on consumption patterns that determine the number of livestock required to meet needs for dairy, beef and lamb.
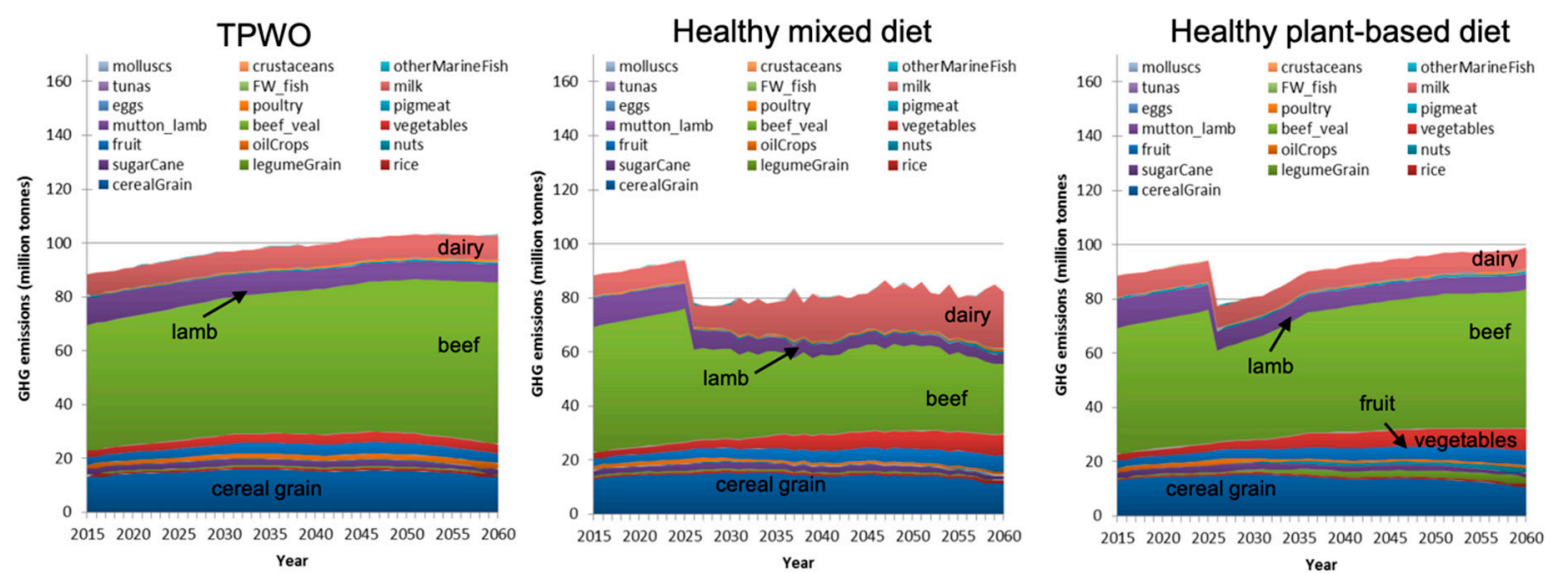

Figure 15. Greenhouse gas emissions by food type for different diets based on domestic agricultural production for different diet scenarios (a) The Path We're On, (b) healthy mixed diet, (c) healthy plant-based diet.

The production of cereal grain also makes a significant contribution to GHGEs. This is due to emissions associated with nitrous oxide emissions from broadacre cropping.

Despite the differences in direct agricultural emissions (Figure 13a) and the fact that they are historically a large component of overall emissions, the effect on future economy-wide emissions is negligible (Figure 13b). This is because the scenarios see the projected growth in emissions from other sectors that dominate the overall total emissions.

5.2.7. Fuel and Energy Use across Different Diet Scenarios for Domestic Consumption and Agricultural Production

This section focuses on fuel and energy use for production only and does not include fuel use for transport or for the production of fossil fuel-based fertilisers. Fuel use for transport is only a small percentage of overall use and there is also insufficient data to determine if food transport is for domestic consumption or for export.

The only significant difference in energy/fuel use between the scenarios is when use is attributed directly to domestic food consumption, in which case the plant-based diet results in the lowest use of 
energy, while the mixed diet is somewhat higher than TPWO (Figure 16). Fuel use is mainly attributed to cropping activity, but a large proportion of crops produced in the HM diet are for animal feed, so higher fuel use is linked to the consumption of livestock products. Both HPB and TPWO diets have lower or no animal products, so fuel use is lower compared to the HM diet.

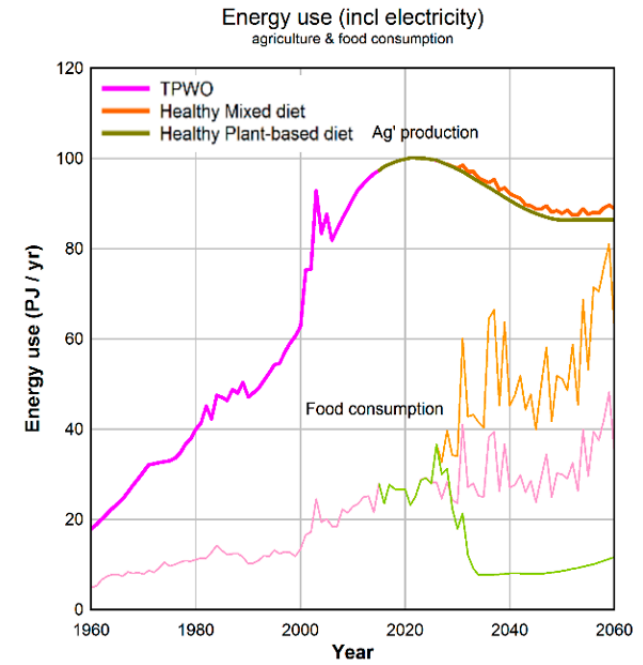

(a)

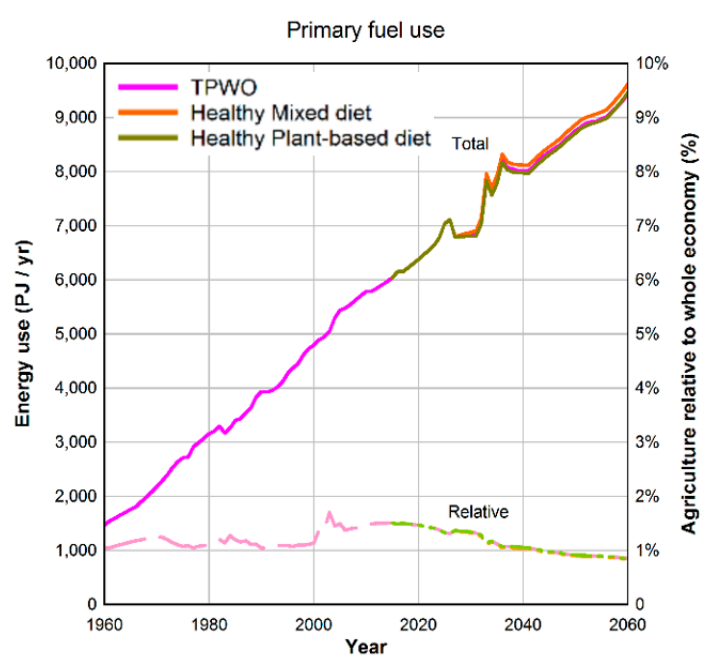

(b)

Figure 16. Energy use by (a) agriculture and the attribution to Australian food consumption and (b) total primary fuel use across the economy, with agricultural share on right hand side.

Although fuel use from agricultural production is not significant compared to fuel use across the rest of the economy, it is essential. Fuel is required to power tractors and other machinery, which, unlike other fuel usage for stationary energy generation across the economy, cannot easily be substituted with renewable alternatives. Australia agricultural production is heavily reliant on fossil-fuel-based fertilisers [30]. It also depends on imports for over half of the oil it consumes, making the agricultural sector very vulnerable to rising oil costs [47]. Any future fluctuations could be detrimental to the sustainability and resilience of agricultural production.

\subsubsection{Fertiliser Use across Different Diet Scenarios for Domestic Consumption and Agricultural} Production

Both alternative healthy diets result in higher fertiliser use than TPWO, with the plant-based diet yielding the greatest dependence (Figure 17a). Higher fertiliser use in the HM and HPB diet scenarios is primarily due to the fact that more fertiliser-intensive crops such as vegetables and fruit, as well as nuts in the HPB scenario, are being produced for domestic consumption (Figure 17b), although it is mitigated somewhat by decreases in sugar production. The sharp upward trend after 2050 can be directly linked to the runaway land degradation discussed in Section 4.2.1. The leveling out of the curve for overall agricultural production in the TPWO scenario around 2050 (Figure 17a) is due to limits to agricultural land availability being reached. 


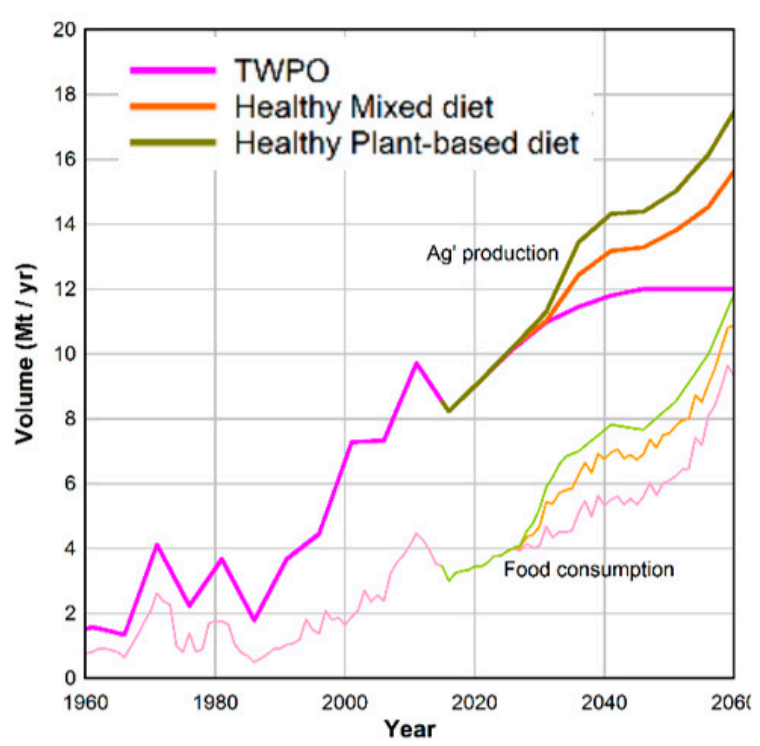

(a)

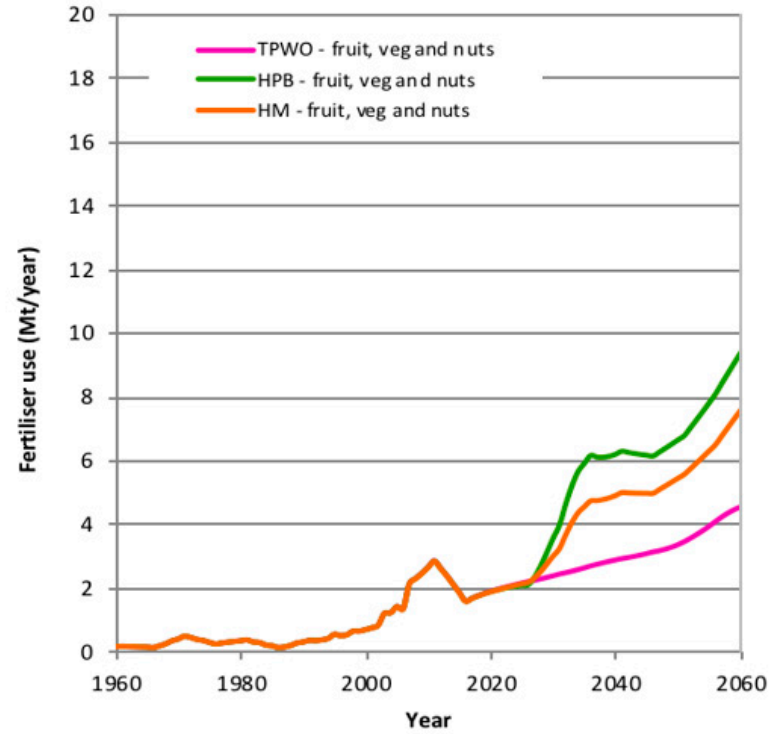

(b)

Figure 17. Fertiliser use by (a) agriculture and the attribution to Australian food consumption and (b) fertilizer use for fruit, vegetables and nuts.

\section{Discussion}

Tables 1 and 2 show a comparative summary of the results from each stage of this study. Aspects such as diet composition, aggregate food consumption, and direct food availability from each alternative diet scenario are qualified in comparison to the TPWO diet scenario in Table 1. Resource use, greenhouse gas emissions, fuel use and fertilizer use from each alternative diet scenario are qualified in comparison to the TPWO diet scenario, the total agricultural sector and the total economy in Table 2. These aspects are then discussed further below.

Table 1. Comparison of diet composition, aggregate food consumption and direct food availability.

\begin{tabular}{ccc}
\hline & HM Compared to TPWO & HPB Compared to TPWO \\
\hline Amount of meat in diet & Lower & No meat \\
Amount of dairy in diet & Higher & No dairy \\
Amount of non-livestock products & Higher & Much higher \\
Direct food availability & Higher & Higher \\
\hline
\end{tabular}

Table 2. Comparison of HM and HPB scenarios to TPWO for resource use, GHG emissions, fuel use and fertilizer use based on domestic consumption, total agricultural production and total economy.

\begin{tabular}{ccccccc}
\hline & \multicolumn{2}{c}{ Domestic Consumption } & \multicolumn{2}{c}{ Total Agricultural Sector } & \multicolumn{2}{c}{ Total Economy } \\
\hline & HM & HPB & HM & HPB & HM & HPB \\
\hline Water use & Higher & Higher & Higher & Higher & Comparable & Higher \\
Land Use & Higher & Lower & Lower & Lower & - & - \\
GHG emissions & Higher & Lower & Lower & Lower & Comparable & Comparable \\
Energy use & Higher & Lower & Higher & Equal & Higher & Equal \\
Fertiliser use & Higher & Higher & Higher & Higher & - & - \\
\hline
\end{tabular}

\subsection{Environmental Pressures of Domestic Food Consumption}

When looking at the environmental footprint of domestic consumption only, it was found that moving from the current (TPWO) to an alternative healthy mixed (HM) diet had negative environmental impacts for four out of the five environmental variables considered (water and land use, GHG emissions and fuel use). However, moving to the HPB diet showed significant positive environmental impacts for three of the five variables (land use, GHGEs and fuel use) and comparable water use with the current 
TPWO diet. These results support the findings of Aleksandrowicz et al. [48] that plant-based diets are the most effective in reducing land use and GHGEs, and that reductions in environmental impacts of diets are generally proportional to the amount that animal products were restricted rather than its 'healthiness'. However, they do not support the results for GHGEs from another Australian study by Hendrie et al. [14], which found that a healthy mixed diet had 25\% lower GHG emissions compared to a 'current norm' diet. The discrepancy can be explained by the fact that the 'current norm' diet was based on the results of the 1995 Nutritional Nutrition Survey, which had higher red meat consumption that the TPWO diet in this study due to a historical trend of decreasing red meat consumption. They also do not support the findings of Vieux et al. [20] who found that substituting animal products with plant-based foods is of no benefit to the environment due to the large amount of fruits and vegetables needed to make up the calorie shortfall. The discrepancy can be explained by the fact that in this study animal products were largely substituted with legumes, rather than a mix of fruit and vegetables as was done by Vieux et al., which have a lower carbon footprint.

The environmental footprint estimate for this study was conservative as it was based on production only and did not include food processing or transport. Research indicates that land and water use for food processing are relatively small compared to agricultural resource use, around $2 \%$ of water use [49] and insignificant land use. It is difficult to isolate the GHGEs associated with food processing because much of the indirect emissions are accounted for in other sectors (such as emissions associated with electricity and other stationary energy generation). This could be a point of difference in GHGE footprint between diets with more processed foods and those without, however, there is no data available to enable isolation of food processing emissions. Although fuel use and GHGEs associated with transporting food may be significant, again no data is available that separates food transport from other forms of transport. These are recognised as limitations of this study and an area for further research.

\subsection{Direct Food Availability}

Direct food availability and subsequent export capability are affected not by whether the diet is healthy or not, but whether it includes animal products. For this reason, the HPB diet has the best result in terms of long-term direct food availability (self-sufficiency) and export capability, which has implications for Australia's future resilience and that of other countries reliant on Australia's exports, adding an extra dimension to the 'healthy and sustainable' debate. With such a low environmental impact, there are ample resources available to produce enough food for the Australian population from within national borders, including highly perishable food such as fruit and vegetables, with some leftover for export. This would potentially reduce Australia's vulnerability to disruptions in global food supply and rises in global food prices. By maintaining sufficient export capability, rises in global food prices and increased demand may even be advantageous for the Australian economy. In the context of a downturn in the mining industry's contribution to the economy [50] and already having established strong demands for its food exports, food production may contribute more significantly to GDP than it does now. Having land available, outside of which is required to feed the population, is also important when considering the need to protect and increase biodiversity. Increasing and maintaining biodiversity has many benefits for agricultural production such as pest control, reduced reliance on outside resources such as imported feed and chemical fertilisers, and crop pollination [51], further increasing Australia's future food system resilience.

One area of vulnerability for the HPB diet, and any healthy diet prescribing increased fruit and vegetable intake is available land suitable for intensive cropping. Turner et al. [33] found that the combined effects of climate change and land degradation would reduce the average yield per hectare for vegetables from $19 \mathrm{t} / \mathrm{ha}$ in 2020 to $15 \mathrm{t} / \mathrm{ha}$ in 2060, with the effects becoming more pronounced over longer time frames. This would mean that by $2060,27 \%$ more land would be required to produce the same amount of food even without any increase in population. Since much of the land suitable for intensive cropping is on the outskirts of cities, where there is intense competition for land from 
other sectors such as housing, this factor poses a serious problem for direct food availability and has implications for urban planning policy.

Another related area of vulnerability in the HPB diet scenario is increasing fertiliser dependence due to industrialised farming methods, nutrient-poor soils and land degradation in Australia. Rising global demand and diminishing reserves of finite resources required to produce fertilisers mean that many may not be either affordable or available in the future. This combined with the low availability of arable land suggests that methods need to be employed to reduce fertiliser dependence, address land degradation, improve biodiversity, and maintain productivity, such as agro-ecological farming methods such as polyculture farming (the planting of two or more crops in the same field at the same time, see [52]) and crop-livestock integration (also known as crop-pasture rotation systems). Expert studies of the global context have recommended moving to more agro-ecological production methods to ensure future food security $[53,54]$. Research worldwide and in Australia specifically has also shown that agro-ecological practices had positive environmental and economic benefits $[55,56]$.

This is a 'minimalist' approach to securing a healthy diet in the sense that the authors only explore the implications of the population eating a healthy diet that is able to be supplied domestically ("direct food availability"). This, along with continued production of excess for export where possible, may still result in production or environmental pressures that are unsustainable. Subsequently, greater interventions can be explored in more complex scenarios that aim to achieve wider objectives, such as relieving environmental pressures ("indirect food availability").

\subsection{Environmental Pressures in the Context of the Total Agricultural Sector}

When looking at the environmental impact of the total agricultural sector, the changes attributable to changes in domestic consumption are generally dwarfed by the national agricultural totals because the rest of the agricultural land is still considered productive and significant surplus is exported. The difference between the food consumption components and the agricultural production reflects the resource use or environmental pressure due to (net) exports of agricultural commodities, some of which are particularly resource and GHGE intensive such as beef. To actually achieve significant resource or environmental improvements in the agricultural sector would require healthy diet strategies to be complemented with consideration of changes to both trade and domestic production. In addition to this, they would also depend on how any 'freed up' land was managed. When looking at the bigger picture, it becomes clear that domestic consumption behaviour is only one piece of the puzzle.

\subsection{Environmental Pressures in the Context of the Total Australian Economy}

In terms of environmental impact on the overall physical economy in Australia, changes to the national diet have an even smaller affect. The results suggest that changes in diet account for less than $10 \%$ and $1 \%$ of overall water and fuel use respectively, and between $1-3 \%$ of GHGEs, meaning that the majority of resource use and emission generation in these areas is attributable to other sectors. This indicates that along with dietary change, it will be necessary to intervene at significant points in other sectors to reduce environmental resource use across the Australian physical economy and mitigate greenhouse gas emissions. Based on national emissions figures from 2016 [57], emissions from electricity generation account for $35 \%$ of the national total, along with $17 \%$ from the transport sector. This suggests that reducing energy consumption, shifting to cleaner, less-GHG intensive energy generation and transitioning to a more efficient transport fleet could have a significant impact on GHGEs.

Findings from the original TPWO study [33] also show that forecast coal seam gas (CSG) operations may cause a dramatic increase in overall water use. The volume of water involved in approximately equivalent to that used by agriculture. This water is drawn from deep aquifers so it will not compete with surface water use. However, the lowering of sub-surface water tables and the potential for contamination of water resources may have a negative impact on agriculture. It may be necessary 
to examine the proposed benefits and costs of CSG in the context of increasing water scarcity and domestic demand for food.

\subsection{Health Implications}

Although the vegan HPB diet has the least negative environmental impact and best long-term direct food availability, it may not be healthy in practice. Vegetarian and vegan diets that are well planned can be nutritionally adequate [42]. However, as noted by Van Dooren et al. [18], the potential for micronutrient deficiencies if a vegan diet is not well planned is high. There is also evidence to suggest that consumer acceptance of vegan diets is likely to be low [58]. Along with the potential need for livestock agro-ecology to reduce fertiliser dependence, this indicates that a semi-vegetarian diet with minimal dairy and red meat may be the most realistic healthy, sustainable and resilient option for the Australian population, in line with the EAT Lancet dietary recommendations. However, more research is needed to determine the composition and associated environmental impacts, and potential for agro-ecology to reduce the need for fertilisers. To maintain direct food availability, it may also be necessary to explore the potential for additional production in regions where the particular crops have not been extensively grown previously, but where there is available cropland. This analysis could occur alongside the exploration of potential movements of agricultural types as an adaptation to climate change.

\subsection{Policy Considerations}

The results raise several considerations for planning and implementing food and nutrition policy. Although dietary guideline recommendations provide a robust evidence base for promoting healthy eating, they need to be complimented with a broader food systems dimension to policy to protect the security of the food supply from which that healthy diet can be selected. Coherent food system-oriented policy approaches are necessary to tackle the social, political and environmental determinants of non-communicable diseases and food insecurity in an equitable manner [59,60], and need to be coordinated across multiple sectors and levels of government [61,62].

\section{Conclusions}

This study has shown that implementing healthy diet strategies in the Australian context has some impact on protecting food availability and reducing environmental impacts but is minimal compared to the potential for change in other areas.

Reducing environmental impacts and achieving direct food availability depend on the proportion of animal products in the diet rather than its 'healthiness'. The healthy plant-based diet (i.e., vegan diet) showed the most potential to reduce the resources required to feed the population and mitigate associated greenhouse gas emissions. From an economic perspective, adopting a healthy plant-based diet would help to maintain export capability. All of these factors combined would reduce Australia's vulnerability to anticipated disruptions in the global food supply.

Key environmental vulnerabilities exist for the healthy plant-based diet scenario. These include fertiliser dependence and land availability for intensive cropping to supply all the necessary components of a healthy diet, particularly fruit and vegetables. Addressing land degradation is important in managing this problem since it is directly related to increasing fertiliser use and decreasing crop yields per hectare. The modelling shows that significant thresholds will be crossed in 2050, tipping Australia into runaway land degradation, unless changes are made to production methods to reverse this trend, such as agro-ecological practices. Likewise, the loss of agricultural land around cities due to competition with other land uses is a key contributing factor to the lack of land availability. There is a need for future availability considerations to be considered in urban planning policies.

Problems with the healthy plant-based diet scenario also exist in terms of consumer acceptance and the high potential for micronutrient deficiencies if not well managed. Furthermore, with a potential need for livestock for some forms of agro-ecology, this indicates that a semi-vegetarian diet with 
minimal dairy and red meat may be the most realistic healthy and sustainable option for the Australian population. However, more research is needed to determine the best composition of diet in terms of health, resource use and direct food availability. This would ideally include exploring the potential for additional production in regions where the particular crops have not been extensively grown previously, but where there is available cropland, as well as the potential benefits in environmental impacts by repurposing any surplus land for carbon sequestration.

It was also found that the impacts of changing domestic diets are dwarfed by overall resource use in the agricultural sector and for the total Australian economy. This further supports the need to modify agricultural production methods, as well as address resource use intensities across other sectors, particularly water use.

Author Contributions: Conceptualization, S.C., K.L., G.T., K.W., S.F. and M.L.; methodology, G.T., M.L. and S.C.; validation, G.T., and S.C.; formal analysis, G.T. and S.C.; writing-original draft preparation, S.C., G.T., K.W., J.S. and M.L.; writing-review and editing, S.C., G.T., K.L., K.W., S.F., K.L. and M.L.; visualization, G.T. and S.C.; supervision, M.L.; project administration, M.L. and K.L.; funding acquisition, M.L. and K.L.

Funding: Lawrence, Friel, Turner, Larsen, Candy, Wingrove and Steenkamp were researchers within an Australian Research Council Linkage Project, 'Modelling policy interventions to protect Australia's food security in the face of environmental sustainability challenges' (LP120100168). Turner was a Senior Research Fellow in the Melbourne Sustainable Society Institute. Open access funding provided by University of Helsinki.

Acknowledgments: The authors would like to recognise the technical guidance of whatIf? Technologies ${ }^{\circledR}$ who are the originators of the software used in the modelling. The authors would also like to thank several anonymous reviewers for improvements to the manuscript.

Conflicts of Interest: The authors declare no conflict of interest.

\section{Appendix A}

Table A1. Summary of scenario creation processes used in the ASFF.

\begin{tabular}{l} 
Re-Allocation of Production \\
\hline Livestock numbers and the relative proportion of type of crop are adjusted with the objective of securing \\
sufficient production to cover domestic consumption in all food categories. This equates to making net \\
imports (imports-exports) zero. The total crop area within each SD is maintained as that in the background \\
scenario. This area includes sown pasture as grazing land for livestock, and hay and silage production \\
dedicated for livestock feed. Livestock also consume cereals, oil crops, and legumes, according to the \\
different type of livestock and feed rates and diet shares. Consequently, it is necessary to allow for this \\
interaction in an iterative process.
\end{tabular}

First, additional livestock are created where net imports of livestock products

livestock exist, allowing for different livestock production rates. If there are excess livestock numbers (i.e., producing net exports), which are fed on the same inputs as the required additional livestock, then these excess stock are reduced by an amount equivalent to the feed required by the additional livestock.

Total domestic consumption of crops (by the population and the newly adjusted livestock) is compared with background production, and where consumption is

crop activity share greater than production, the ratio is used to scale those deficient crop areas within the total crop area in each SD. Crop areas yielding excess production occupy the remaining area in each SD, in their original proportion by area.

Should crop production still be deficient, livestock numbers are readjusted to make sown pasture available (with dairy excluded) for those crops in need. This only applies to livestock that graze sown pasture and where there are net

livestock; crop activity share exports of associated livestock products. The area of sown pasture available is based on the volume of feed required for the excess livestock. New crop area required is calculated as above, and the sown pasture decreased by this amount; from which the new share of crop activity is calculated. Livestock numbers are readjusted according to the proportional decrease in sown pasture. 


\section{References}

1. Fedoroff, N.V. Food in a Future of 10 Billion. Agric. Food Secur. 2015, 4, 11. [CrossRef]

2. Godfray, H.C.J.; Beddington, J.R.; Crute, I.R.; Haddad, L.; Lawrence, D.; Muir, J.F.; Pretty, J.; Robinson, S.; Thomas, S.M.; Toulmin, C. Food Security: The Challenge of Feeding 9 Billion People. Science 2010, 327, 812-818. [CrossRef] [PubMed]

3. Wu, S.-H.; Ho, C.-T.; Nah, S.-L.; Chau, C.-F. Global Hunger: A Challenge to Agricultural, Food, and Nutritional Sciences. Crit. Rev. Food Sci. Nutr. 2014, 54, 151-162. [CrossRef] [PubMed]

4. Pelletier, N.; Tyedmers, P. Forecasting potential global environmental costs of livestock production 2000-2050. Proc. Natl. Acad. Sci. USA 2010, 107, 18371-18374. [CrossRef] [PubMed]

5. Rockström, J.; Steffen, W.L.; Noone, K.; Persson, Å.; Chapin, F.S., III; Lambin, E.; Lenton, T.M.; Scheffer, M.; Folke, C.; Schellnhuber, H.J.; et al. Planetary boundaries: Exploring the safe operating space for humanity. Ecol. Soc. 2009, 14, 1-33. [CrossRef]

6. Auestad, N.; Fulgoni, V.L. What current literature tells us about sustainable diets: Emerging research linking dietary patterns, environmental sustainability, and economics. Adv. Nutr. Int. Rev. J. 2015, 6, 19-36. [CrossRef]

7. Hallström, E.; Carlsson-Kanyama, A.; Börjesson, P. Environmental impact of dietary change: A systematic review. J. Clean. Prod. 2015, 91, 1-11. [CrossRef]

8. Joyce, A.; Hallett, J.; Hannelly, T.; Carey, G. The impact of nutritional choices on global warming and policy implications: Examining the link between dietary choices and greenhouse gas emissions. Energy Emiss. Control Technol. 2014, 2, 33-43. [CrossRef]

9. Van de Ven, D.-J.; González-Eguino, M.; Arto, I. The potential of behavioural change for climate change mitigation: A case study for the European Union. Mitig. Adapt. Strateg. Glob. Chang. 2017. [CrossRef]

10. Green, R.; Milner, J.; Dangour, A.D.; Haines, A.; Chalabi, Z.; Markandya, A.; Spadaro, J.; Wilkinson, P. The potential to reduce greenhouse gas emissions in the UK through healthy and realistic dietary change. Clim. Chang. 2015, 129, 253-265. [CrossRef]

11. Fellmann, T.; Witzke, P.; Weiss, F.; Van Doorslaer, B.; Drabik, D.; Huck, I.; Salputra, G.; Jansson, T.; Leip, A. Major challenges of integrating agriculture into climate change mitigation policy frameworks. Mitig. Adapt. Strateg. Glob. Chang. 2018, 23, 451-468. [CrossRef] [PubMed]

12. Friel, S.; Barosh, L.J.; Lawrence, M. Towards healthy and sustainable food consumption: An Australian case study. Public Health Nutr. 2013, 1-11. [CrossRef] [PubMed]

13. Hadjikakou, M. Trimming the excess: Environmental impacts of discretionary food consumption in Australia. Ecol. Econ. 2017, 131, 119-128. [CrossRef]

14. Hendrie, G.A.; Ridoutt, B.G.; Wiedmann, T.O.; Noakes, M. Greenhouse gas emissions and the Australian diet-Comparing dietary recommendations with average intakes. Nutrients 2014, 6, 289-303. [CrossRef]

15. FAO. Food Wastage Footprint: Impacts on Natural Resources-Summary Report; Food and Agriculture Organisation of the United Nations: Rome, Italy, 2013.

16. Fazeni, K.; Steinmuller, H. Impact of changes in diet on the availability of land, energy demand. Energy Sustain. Soc. 2011, 1, 1-14. [CrossRef]

17. Macdiarmid, J.I.; Kyle, J.; Horgan, G.W.; Loe, J.; Fyfe, C.; Johnstone, A.; McNeill, G. Sustainable diets for the future: Can we contribute to reducing greenhouse gas emissions by eating a healthy diet? Am. J. Clin. Nutr. 2012, 96, 632-639. [CrossRef]

18. Van Dooren, C.; Marinussen, M.; Blonk, H.; Aiking, H.; Vellinga, P. Exploring dietary guidelines based on ecological and nutritional values: A comparison of six dietary patterns. Food Policy 2004, 44, 36-46. [CrossRef]

19. Tom, M.S.; Fischbeck, P.S.; Hendrickson, C.T. Energy use, blue water footprint, and greenhouse gas emissions for current food consumption patterns and dietary recommendations in the US. Environ. Syst. Decis. 2015. [CrossRef]

20. Vieux, F.; Darmon, N.; Touazi, D.; Soler, L.G. Greenhouse gas emissions of self-selected individual diets in France: Changing the diet structure or consuming less? Ecol. Econ. 2012, 75, 91-101. [CrossRef]

21. Willett, W.; Rockström, J.; Loken, B.; Springmann, M.; Lang, T.; Vermeulen, S.; Garnett, T.; Tilman, D.; DeClerck, F.; Wood, A.; et al. Food in the Anthropocene: The EAT-Lancet Commission on healthy diets from sustainable food systems. Lancet 2019, 393, 447-492. [CrossRef] 
22. Lawrence, M.A.; Baker, P.I.; Pulker, C.E.; Pollard, C.M. Sustainable, resilient food systems for healthy diets: The transformation agenda. Public Health Nutr. 2019, 1-5. [CrossRef] [PubMed]

23. DAFF. National Food Plan: Our Food Future; Department of Agriculture Fisheries and Forestry, Australian Government: Canberra, Australia, 2013.

24. PMSEIC. Australia and Food Security in a Changing World; The Prime Minister's Science, Engineering and Innovation Council: Canberra, Australia, 2010.

25. Moir, B.; Morris, P. Global Food Security: Facts, Issues and Implications; Australian Bureau of Agricultural and Resource Economics and Sciences: Canberra, Australia, 2016.

26. Farmar-Bowers, Q. Finding Ways to Improve Australia's Food Security Situation. Agriculture 2015, 5, $286-312$. [CrossRef]

27. Lawrence, G.; Richards, C.; Burch, D. The impacts of climate change on Australia's food production and export. In Food Security in Australia: Challenges and Prospects; Farmar-Bowers, Q., Higgins, V., Millar, J., Eds.; Springer: New York, NY, USA, 2013; pp. 173-186.

28. Turner, G.M.; Dunlop, M.; Candy, S. The impacts of expansion and degradation on Australian cropping yields-An integrated historical perspective. Agric. Syst. 2016, 143, 22-37. [CrossRef]

29. Qureshi, M.E.; Hanjra, M.A.; Ward, J. Impact of water scarcity in Australia on global food security in an era of climate change. Food Policy 2013, 38, 136-145. [CrossRef]

30. Henzell, T. Australian Agriculture: Its History and Challenges; CSIRO Publishing: Collingwood, Australia, 2007.

31. Lawrence, G.; Richards, C.; Lyons, K. Food security in Australia in an era of neoliberalism, productivism and climate change. J. Rural Stud. 2012. [CrossRef]

32. Ridoutt, B.; Baird, D.; Bastiaans, K.; Darnell, R.; Hendrie, G.; Riley, M.; Sanguansri, P.; Syrette, J.; Noakes, M.; Keating, B. Australia's nutritional food balance: Situation, outlook and policy implications. Food Secur. 2017, 9, 211-226. [CrossRef]

33. Turner, G.M.; Larsen, K.A.; Candy, S.; Ogilvy, S.; Ananthapavan, J.; Moodie, M.; James, S.W.; Friel, S.; Ryan, C.J.; Lawrence, M.A. Squandering Australia's food security-The environmental and economic costs of our unhealthy diet and the policy Path We're On. J. Clean. Prod. 2018, 195, 1581-1599. [CrossRef]

34. ABS. Australian Health Survey: Nutrition First Results: Foods and Nutrients 2011-2012; Australian Bureau of Statistics, Commonwealth of Australia: Canberra, Australia, 2014.

35. DAFF. Australian Food Statistics 2012-2013; Department of Agriculture, Forests and Fisheries, Commonwealth of Australia: Canberra, Australia, 2014.

36. Blackstone, N.T.; El-Abbadi, N.H.; McCabe, M.S.; Griffin, T.S.; Nelson, M.E. Linking sustainability to the healthy eating patterns of the Dietary Guidelines for Americans: A modelling study. Lancet Planet. Health 2018, 2, e344-e352. [CrossRef]

37. Turner, G.M.; Hoffman, R.; McInnis, B.C.; Poldy, F.; Foran, B. A tool for strategic biophysical assessment of a national economy-The Australian stocks and flows framework. Environ. Model. Softw. 2011, 26, 1134-1149. [CrossRef]

38. Hadjikakou, M.; Ritchie, E.G.; Watermeyer, K.E.; Bryan, B.A. Improving the assessment of food system sustainability. Lancet Planet. Health 2019, 3, e62-e63. [CrossRef]

39. Mietzner, D.; Reger, G. Advantages and disadvantages of scenario approaches for strategic foresight. Int. J. Technol. Intell. Plan. 2005, 1, 220-239. [CrossRef]

40. Reilly, M.; Willenbockel, D. Managing uncertainty: A review of food system scenario analysis and modelling. Philos. Trans. R. Soc. B Biol. Sci. 2010, 365, 3049-3063. [CrossRef] [PubMed]

41. Saltelli, A.; Piano, S.L. Problematic Quantifications: A Critical Appraisal of Scenario Making for a Global 'Sustainable' Food Production. Food Ethics 2017, 1, 173-179. [CrossRef]

42. NHMRC. Australian Dietary Guidelines; National Health and Medical Research Council: Canberra, Australia, 2013.

43. Larsen, K.; Turner, G.M.; Ryan, C.; Lawrence, M. Victorian Food Supply Scenarios: Impacts on Availability of a Nutritious Diet; Victorian Eco-Innovation Lab (VEIL), University of Melbourne: Melbourne, Australia, 2011.

44. Röös, E.; Bajželj, B.; Smith, P.; Patel, M.; Little, D.; Garnett, T. Greedy or needy? Land use and climate impacts of food in 2050 under different livestock futures. Glob. Environ. Chang. 2017, 47, 1-12. [CrossRef]

45. Pollack, S. Food Waste Reduction Program WRF 2.52 (Food Know How); Cultivating Community and City of Yarra: Melbourne, Australia, 2014.

46. AIHW. Australia's Food and Nutrition; Australian Institute of Health of Welfare: Canberra, Australia, 2012. 
47. Eadie, L.; Stone, C. Farming Smarter not Harder; Centre for Policy Development: Sydney, NSW, Australia, 2012; Available online: http://tinyurl.com/k9vwu3b (accessed on 10 December 2019).

48. Aleksandrowicz, L.; Green, R.; Joy, E.J.; Smith, P.; Haines, A. The Impacts of Dietary Change on Greenhouse Gas Emissions, Land Use, Water Use, and Health: A Systematic Review. PLoS ONE 2016, 11, e0165797. [CrossRef] [PubMed]

49. Wallis, D.; Brook, P.; Thompson, C. Water Sustainability in the Australian Food Processing Industry, Australian Food Statistics; Department of Agriculture, Fisheries and Forestry: Canberra, Australia, 2007.

50. Duke, J. 2018 'The End' of Resources Boom as Commodity Price Drops Bite; The Sydney Morning Herald: Sydney, NSW, Australia, 2018.

51. Dudley, N.; Alexander, S. Agriculture and biodiversity: A review. Biodiversity 2017, 18, 45-49. [CrossRef]

52. McSorley, R. Polyculture. In Encyclopedia of Entomology; Capinera, J.L., Ed.; Springer: Dordrecht, The Netherlands, 2008; pp. 2986-2989. [CrossRef]

53. IAASTD. Synthesis Report: A Synthesis of the Global and Sub-Global IAASTD Reports; Island Press: Washington, DC, USA, 2009.

54. UNCTAD. Trade and Environment Review 2013, Wake up before It Is too Late-Make Agriculture Truly Sustainable Now for Food Security in a Changing Climate; United Nations: Geneva, Switzerland, 2013.

55. Scherr, S.; McNelly, J.A.; Shames, S. Ecoagriculture: Agriculture, Environmental Conservation, and Poverty Reduction at a Landscape Scale (Chapter 3). In The Role of the Environment in Poverty Alleviation; Galizzi, P., Ed.; Fordham University Press: New York, USA, 2008.

56. Seis, C. Pasture cropping as a means to managing land. Aust. Org. J. Winter 2006, 2006, 42-43.

57. Department of the Environment and Energy. Quarterly Update of the National Greenhouse Gas Inventory: June 2016; Commonwealth of Australia: Canberra, Australia, 2016.

58. Hoek, A.C.; Pearson, D.; James, S.; Lawrence, M.; Friel, S. Shrinking the food-print: A qualitative study into consumer perceptions, experiences and attitudes towards healthy and environmentally friendly food behaviours. Appetite 2017, 108, 117-131. [CrossRef]

59. Global Panel on Agriculture and Food Systems for Nutrition. Food Systems and Diets: Facing the Challenges of the 21st Century; Global Panel on Agriculture and Food Systems for Nutrition: London, UK, 2016; Available online: http://glopan.org/sites/default/files/ForesightReportDec2016.pdf (accessed on 10 December 2019).

60. Dangour, A.D.; Mace, G.; Shankar, B. Food systems, nutrition, health and the environment. Lancet Planet. Health 2017, 1, e8-e9. [CrossRef]

61. FAO/WHO. Second International Conference on Nutrition: Framework for Action; Food and Agriculture Organization of the United Nations, World Health Organization: Rome, Italy, 2014; Available online: http://www.fao.org/3/a-mm215e.pdf (accessed on 10 December 2019).

62. FAO/WHO. Second International Conference on Nutrition: Rome Declaration on Nutrition; Food and Agriculture Organization of the United Nations, World Health Organization: Rome, Italy, 2014; Available online: http://www.fao.org/3/a-ml542e.pdf (accessed on 10 December 2019).

(C) 2019 by the authors. Licensee MDPI, Basel, Switzerland. This article is an open access article distributed under the terms and conditions of the Creative Commons Attribution (CC BY) license (http://creativecommons.org/licenses/by/4.0/). 